\title{
Determination of the Impact of Glycolate on ARP and MCU Operations
}

K. M. L. Taylor-Pashow

T. B. Peters

T. C. Shehee

June 2012

Savannah River National Laboratory Savannah River Nuclear Solutions, LLC Aiken, SC 29808

Prepared for the U.S. Department of Energy under contract number DE-AC09-08SR22470. 
SRNL-STI-2012-00218

Revision 0

\section{DISCLAIMER}

This work was prepared under an agreement with and funded by the U.S. Government. Neither the U.S. Government or its employees, nor any of its contractors, subcontractors or their employees, makes any express or implied:

1. warranty or assumes any legal liability for the accuracy, completeness, or for the use or results of such use of any information, product, or process disclosed; or

2. representation that such use or results of such use would not infringe privately owned rights; or

3. endorsement or recommendation of any specifically identified commercial product, process, or service.

Any views and opinions of authors expressed in this work do not necessarily state or reflect those of the United States Government, or its contractors, or subcontractors.

\section{Printed in the United States of America \\ Prepared for U.S. Department of Energy}


Keywords: $M S T$, $m M S T$, $A R P$, MCU, glycolate

Retention: Permanent

\section{Determination of the Impact of Glycolate on ARP and MCU Operations}

K. M. L. Taylor-Pashow

T. B. Peters

T. C. Shehee

June 2012

Savannah River National Laboratory Savannah River Nuclear Solutions, LLC Aiken, SC 29808

Prepared for the U.S. Department of Energy under contract number DE-AC09-08SR22470. 


\section{REVIEWS AND APPROVALS}

AUTHORS:

K. M. L. Taylor-Pashow, Separations and Actinide Science Programs

Date

T. B. Peters, Separations and Actinide Science Programs

Date

T. C. Shehee, Separations and Actinide Science Programs

Date

TECHNICAL REVIEW:

D. T. Hobbs, Separations and Actinide Science Programs

Date

APPROVAL:

S. D. Fink, Manager

Date

Separations and Actinide Science Programs

S.L. Marra, Manager

Date

Environmental \& Chemical Process Technology Research Programs

J. E. Occhipinti, Manager

Date

SRR, Waste Solidification Engineering 
SRNL-STI-2012-00218

Revision 0

\section{EXECUTIVE SUMMARY}

Savannah River Remediation (SRR) is evaluating an alternate flowsheet for the Defense Waste Processing Facility (DWPF) using glycolic acid as a reductant. An important aspect of the development of the glycolic acid flowsheet is determining if glycolate has any detrimental downstream impacts. Testing was performed to determine if there is any impact to the strontium and actinide sorption by monosodium titanate (MST) and modified monosodium titanate (mMST) or if there is an impact to the cesium removal at the Modular Caustic-Side Solvent Extraction Processing Unit (MCU).

Sorption testing was performed using both MST and modified MST (mMST) in the presence of 5,000 and 10,000 ppm (mass basis) glycolate. 10,000 ppm is the estimated bounding concentration expected in the DWPF recycle stream based on DWPF melter flammable gas model results. The presence of glycolate was found to slow the removal of $\mathrm{Sr}$ and $\mathrm{Pu}$ by MST, while increasing the removal rate of $\mathrm{Np}$. Results indicate that the impact is a kinetic effect, and the overall capacity of the material is not affected. There was no measurable effect on U removal at either glycolate concentration. The slower removal rates for $\mathrm{Sr}$ and $\mathrm{Pu}$ at 5,000 and 10,000 ppm glycolate could result in lower DF values for these sorbates in ARP based on the current (12 hours) and proposed ( 8 hours) contact times. For the highest glycolate concentration used in this study, the percentage of Sr removed at 6 hours of contact decreased by $1 \%$ and the percentage of $\mathrm{Pu}$ removed decreased by nearly $7 \%$. The impact may prove insignificant if the concentration of glycolate that is returned to the tank farm is well below the concentrations tested in this study.

The presence of glycolate also decreased the removal rates for all three sorbates $(\mathrm{Sr}, \mathrm{Pu}$, and $\mathrm{Np}$ ) by mMST. Similarly to MST, the results for mMST indicate that the impact is a kinetic effect, and the overall capacity of the material is not affected. The presence of glycolate did not change the lack of affinity of mMST for U.

Pre-contacting the MST or mMST with glycolate did not have a significant effect on the performance of the materials when compared to tests having the same concentration of glycolate present in the simulant. These findings suggest that the glycolate is likely influencing removal by sorbate complexation and not by depositing onto or forming a film on the surface of the MST solids.

Since the DF values are salt batch dependent, it is not possible to a priori quantify the impacts of glycolate on future processing campaigns. However, we recommend that the impacts of glycolate be evaluated during each salt batch qualification when a final processing concentration is defined, and recommendations can then be made on how to mitigate negative impacts, if needed. Impacts to the performance of the MST or mMST could be mitigated by increasing contact time or increasing sorbent concentrations.

In addition to the MST and mMST testing, testing was performed to determine if there is an impact to the cesium removal at Modular Caustic-Side Solvent Extraction Processing Unit (MCU). An Extraction-Scrub-Strip (ESS) test routine was used to simulate cesium removal at the MCU. For this, SRNL performed three ESS tests, using the same basic aqueous waste simulant and solvent. For one test, SRNL added 5,000 ppm (mass basis) of glycolate and added 10,000 ppm of glycolate to a second test. A control test contained no glycolate. The results of all three tests were virtually identical for all the extraction, scrub and strip tests. (A single data point in the 5,000 ppm test is physically impossible and SRNL is currently resolving this obvious error.) At 
this time, SRNL concludes that the presence of up to $10,000 \mathrm{ppm}$ of glycolate does not affect cesium removal by the current solvent system used in the MCU.

Although not tested, the impact of glycolate for the Next Generation Solvent - that replaces BOBCalixC6 with MaxCalix - is expected to be very similar to that for the baseline solvent. Testing is needed to confirm.

Additional testing is recommended to both further examine the nature of the interaction of glycolate with MST and mMST and also to help address some postulated risks on ARP/MCU operations with implementation of the glycolate flowsheet. The additional testing includes FTIR and Raman spectroscopy to examine the surface of the MST and mMST particles, iodometric titrations to determine the peroxide content in the mMST before and after exposure to glycolate, particle size measurements of the MST and mMST from the experiments performed with glycolate, and measurements of soluble $\mathrm{Ti}$ in the supernate from these glycolate experiments.

With regards to MCU impacts, the following tests are also recommended based on the premortem risk assessment. First, material compatibility testing should be performed to ensure that glycolate does not negatively affect the physical properties of the various polymers used at MCU. Second, SRNL recommends performing dispersion tests with the glycolate spiked solutions to ensure there is no hydraulic effect on the cesium removal performance. 


\section{TABLE OF CONTENTS}

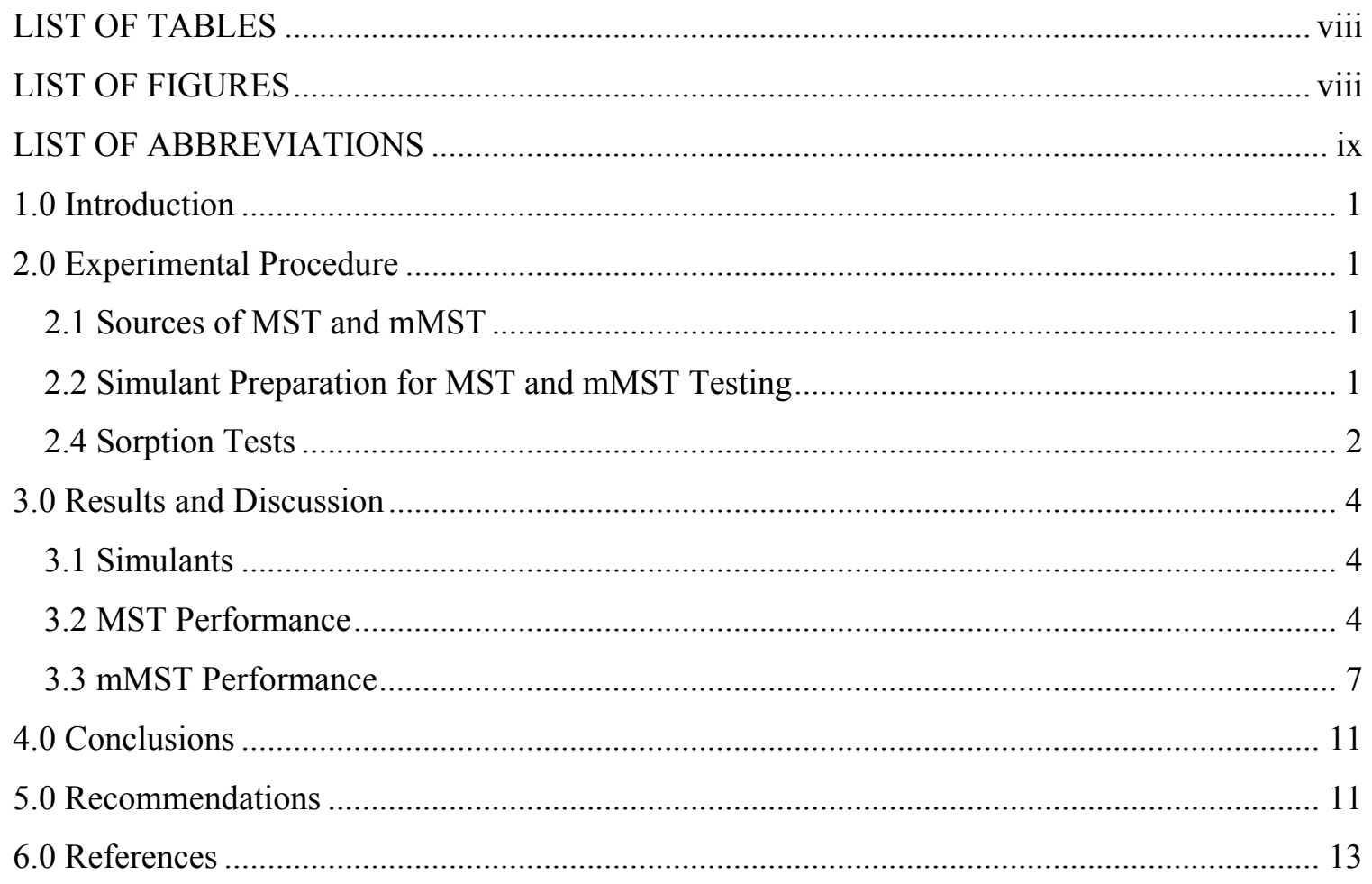




\section{LIST OF TABLES}

Table 2-1. Compositions of Simulated Waste Solution (SWS-5-2009) and Salt Solution (SWS-12010)

Table 2-2. Compositions of Simulated Waste Solutions for the ESS Tests ................................. 2

Table 2-3. Molar Concentrations of Sorbates, Glycolate, and Peroxo Groups on mMST............. 3

Table 3-1. Measured Glycolate Concentrations ....................................................................... 4

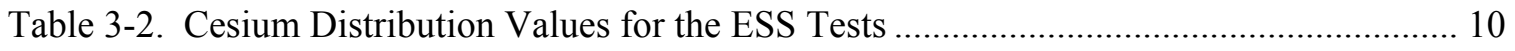

\section{LIST OF FIGURES}

Figure 3-1. Percentage of ${ }^{85} \mathrm{Sr}$ removed versus contact time with MST in the presence of $0 \mathrm{ppm}$ (blue), $5000 \mathrm{ppm}$ (red), and $10000 \mathrm{ppm}$ glycolate in solution (green) or pre-contacted with MST (purple).

Figure 3-2. Percentage of Pu removed versus contact time with MST in the presence of $0 \mathrm{ppm}$ (blue), $5000 \mathrm{ppm}$ (red), and $10000 \mathrm{ppm}$ glycolate in solution (green) or pre-contacted with MST (purple).

Figure 3-3. Percentage of Np removed versus contact time with MST in the presence of $0 \mathrm{ppm}$ (blue), $5000 \mathrm{ppm}$ (red), and $10000 \mathrm{ppm}$ glycolate in solution (green) or pre-contacted with MST (purple).

Figure 3-4. Percentage of ${ }^{85} \mathrm{Sr}$ removed versus contact time with $\mathrm{mMST}$ in the presence of $0 \mathrm{ppm}$ (blue), $5000 \mathrm{ppm}$ (red), and $10000 \mathrm{ppm}$ glycolate in solution (green) or pre-contacted with mMST (purple).

Figure 3-5. Percentage of Pu removed versus contact time with mMST in the presence of $0 \mathrm{ppm}$ (blue), $5000 \mathrm{ppm}$ (red), and $10000 \mathrm{ppm}$ glycolate in solution (green) or pre-contacted with mMST (purple).

Figure 3-6. Percentage of Np removed versus contact time with mMST in the presence of $0 \mathrm{ppm}$ (blue), $5000 \mathrm{ppm}$ (red), and $10000 \mathrm{ppm}$ glycolate in solution (green) or pre-contacted with mMST (purple). 


\section{LIST OF ABBREVIATIONS}

$\begin{array}{ll}\text { ARP } & \text { Actinide Removal Process } \\ \text { DF } & \text { decontamination factor } \\ \text { DWPF } & \text { Defense Waste Processing Facility } \\ \text { ESS } & \text { Extraction-Scrub-Strip } \\ \text { FTIR } & \text { Fourier transform infrared spectroscopy } \\ \text { IC } & \text { ion chromatography } \\ \text { ICP-ES } & \text { inductively couples plasma - emission spectroscopy } \\ \text { ICP-MS } & \text { inductively coupled plasma - mass spectroscopy } \\ \text { MCU } & \text { Modular Caustic-Side Solvent Extraction Processing Unit } \\ \text { MST } & \text { monosodium titanate } \\ \text { mMST } & \text { modified monosodium titanate } \\ \text { PuTTA } & \text { plutonium thenoyltrifluoroacetone scintillation } \\ \text { PVDF } & \text { polyvinylidene fluoride } \\ \text { SEE } & \text { Systems Engineering Evaluation } \\ \text { SRNL } & \text { Savannah River National Laboratory } \\ \text { SRR } & \text { Savannah River Remediation } \\ \text { TTQAP } & \text { Task Technical and Quality Assurance Plan }\end{array}$




\subsection{Introduction}

Savannah River Remediation (SRR) recently conducted a Systems Engineering Evaluation (SEE) to determine the optimum alternate reductant flowsheet for the Defense Waste Processing Facility (DWPF). Specifically, two proposed flowsheets (Nitric/Formic/Glycolic and Nitric/Formic/ Sugar) were evaluated based upon results from preliminary testing. Comparison of the two flowsheets against several weighted technical and business evaluation criteria indicated a preference towards the Nitric/Formic/Glycolic flowsheet. As a result, the Nitric/Formic/Glycolic flowsheet was recommended for further testing. ${ }^{1}$ Subsequently, SRNL demonstrated the viability of a Glycolic/Nitric Acid flowsheet, and SRR is currently proceeding with the development and demonstration of that flowsheet.

An important aspect of the development of the glycolic acid flowsheet is determining if glycolate has any detrimental downstream impacts. Therefore, testing was performed to determine if there is any impact to the strontium and actinide sorption by monosodium titanate (MST) in the Actinide Removal Process (ARP). Testing was also performed to determine the impact to cesium mass transfer in the solvent extraction process in the Modular Caustic Side Solvent Extraction Unit (MCU).

This work was performed at the request of SRR Engineering ${ }^{2}$ and was controlled by a Task Technical and Quality Assurance Plan (TTQAP). ${ }^{3}$

\subsection{Experimental Procedure}

\subsection{Sources of MST and mMST}

The baseline MST used in these studies was prepared using a sol-gel process developed at the Savannah River National Laboratory (SRNL) and supplied by Optima Chemical Group LLC (Douglas, GA, Lot \#00-QAB-417) as a $15 \mathrm{wt} \%$ suspension in water containing 0.10-0.15 M $\mathrm{NaOH}$ and $100-150 \mathrm{mg} \mathrm{L}^{-1} \mathrm{NaNO}_{2}{ }^{4}$. The modified MST (mMST) used in these studies was prepared by the post-synthesis treatment of MST with hydrogen peroxide. The details of this procedure have been previously published. ${ }^{5}$ A $25 \mathrm{~g}$ supply of the mMST (LS-11) was prepared using the Optima-supplied MST.

\subsection{Simulant Preparation for MST and mMST Testing}

The simulant used in this testing was prepared by the addition of glycolate to an already prepared simulant (SWS-5-2009) with the composition shown in Table 2-1. This simulant is considered conservative for measuring the effect of glycolate on MST sorption, due to the lower hydroxide and sodium concentrations. At high hydroxide concentrations, the hydrolysis products of the actinides are expected to be dominant (see Appendix A). Therefore, increasing the sodium and hydroxide concentrations of the simulant would further reduce any interaction of glycolate with the species of interest (i.e., strontium and actinides).

Two glycolate containing simulants were prepared with targeted glycolate concentrations of 10,000 and 5,000 ppm (on a mass basis). $10,000 \mathrm{ppm}$ is the estimated bounding concentration expected in the DWPF recycle stream. ${ }^{6}$ Tests were also performed using simulant that had not been spiked with glycolate for comparison. For the 5,000 ppm glycolate simulant, $2.2870 \mathrm{~g}$ $(0.0233 \mathrm{~mol})$ of sodium glycolate was dissolved in $15 \mathrm{~mL}$ of salt solution (SWS-1-2010, see Table 2-1 for composition). This solution was then added to $350 \mathrm{~mL}$ of SWS-5-2009. The simulant was equilibrated at room temperature for 4 days, after which a sample was removed, filtered, and analyzed for glycolate concentration using ion chromatography (IC). A similar 
procedure was followed to prepare the $10,000 \mathrm{ppm}$ glycolate simulant, using $4.5743 \mathrm{~g}(0.0467$ mol) of sodium glycolate dissolved in $25 \mathrm{~mL}$ of SWS-1-2010. In this case the sodium glycolate did not completely dissolve in the $25 \mathrm{~mL}$ of salt solution, but the suspension was added to the simulant, where the remaining sodium glycolate dissolved. The equilibrated simulants were then used directly for the sorption testing, without filtering.

Table 2-1. Compositions of Simulated Waste Solution (SWS-5-2009) and Salt Solution (SWS-1-2010).

\begin{tabular}{||c|c|c||}
\hline Component & Simulant (SWS-5-2009) & Salt Solution (SWS-1-2010) \\
\hline Free $\mathrm{NaOH}$ & $1.37 \mathrm{M}$ & $1.33 \mathrm{M}$ \\
\hline Total $\mathrm{NaNO}_{3}$ & $2.13 \mathrm{M}$ & $2.90 \mathrm{M}$ \\
\hline $\mathrm{NaAl}(\mathrm{OH})_{4}$ & $0.404 \mathrm{M}$ & - \\
\hline $\mathrm{NaNO}_{2}$ & $0.133 \mathrm{M}$ & $0.149 \mathrm{M}$ \\
\hline $\mathrm{Na}_{2} \mathrm{SO}_{4}$ & $0.483 \mathrm{M}$ & $0.581 \mathrm{M}$ \\
\hline $\mathrm{Na}_{2} \mathrm{CO}_{3}$ & $0.0298 \mathrm{M}$ & $0.029 \mathrm{M}$ \\
\hline $\mathrm{Total} \mathrm{Na}$ & $5.05 \mathrm{M}$ & $5.6 \mathrm{M}$ \\
\hline${ }^{85} \mathrm{Sr}$ & $30,000 \mathrm{dpm} / \mathrm{mL}$ (target) & - \\
\hline Total Sr & $6.85 \times 10^{-6} \mathrm{M}$ & - \\
\hline${ }^{137} \mathrm{Cs}$ & $96,300 \mathrm{dpm} / \mathrm{mL}$ & - \\
\hline Total Cs & $1.26 \times 10^{-4} \mathrm{M}$ & - \\
\hline $\mathrm{Pu}$ & $220 \mu \mathrm{g} / \mathrm{L}$ & - \\
\hline $\mathrm{Np}$ & $460 \mu \mathrm{g} / \mathrm{L}$ & - \\
\hline $\mathrm{U}$ & $10,700 \mu \mathrm{g} / \mathrm{L}$ & - \\
\hline \multicolumn{2}{|l}{}
\end{tabular}

\subsection{Simulant preparation for the ESS test}

Simulant for the ESS test was provided by a previously prepared general purpose simulant. To three bottles $(205 \mathrm{~mL})$ of this material, glycolic acid was added at $0,5,000$, or 10,000 ppm (by mass). The simulants were stirred for three days with no observable precipitation. Each solution was then spiked with enough ${ }^{137} \mathrm{Cs}$ to achieve a final activity of $1.50 \mathrm{E}+05 \mathrm{dpm} / \mathrm{mL}$. See Table 22 for a summary of the composition.

Table 2-2. Compositions of Simulated Waste Solutions for the ESS Tests

\begin{tabular}{||c|c|}
\hline Component & Simulant (M) \\
\hline Free $\mathrm{NaOH}$ & 2.02 \\
\hline Total NaNO & 1.99 \\
\hline $\mathrm{NaAl}(\mathrm{OH})_{4}$ & 0.274 \\
\hline $\mathrm{NO}_{2}$ & 0.490 \\
\hline $\mathrm{SO}_{4}$ & 0.137 \\
\hline $\mathrm{CO}_{3}$ & 0.147 \\
\hline Total Na & 5.47 \\
\hline${ }^{137} \mathrm{Cs}$ & $1.50 \mathrm{E}+05 \mathrm{dpm} / \mathrm{mL}$ \\
\hline
\end{tabular}

\subsection{Sorption Tests}

A total of 20 individual sorption tests were performed. Tests 1-5 were performed using simulant SWS-5-2009 with no glycolate present, tests 6-10 were performed using SWS-5-2009 spiked with 5,000 ppm glycolate, and tests 11-15 were performed with SWS-5-2009 spiked with $10,000 \mathrm{ppm}$ glycolate. $60 \mathrm{~mL}$ of the appropriate simulant were used for each of the tests 1-15. Tests 16-20 represent a more conservative test which was modeled based on previous testing to 
evaluate possible scale inhibitors for the high level waste evaporators. ${ }^{7}$ In this set of tests, samples of MST and mMST were contacted with sodium glycolate overnight (without agitation) prior to adding to the simulated waste solution. The amount of glycolate contacted with the MST and mMST was the amount required to provide a 10,000 ppm solution once the mixture was added to the test bottles containing the simulant. A stock solution of sodium glycolate was prepared by dissolving $4.31073 \mathrm{~g}$ of sodium glycolate in $8.25 \mathrm{~mL}$ of distilled water. Aliquots $(0.95 \mathrm{~mL})$ of this solution were then added to the samples of MST and mMST to be used in tests 16-20. After contacting overnight, the MST/mMST and glycolate mixtures were added to the test bottles containing $38 \mathrm{~mL}$ of SWS-5-2009 each. Table 2-3 provides the molar concentrations of the sorbates compared to the molar concentrations of glycolate and the peroxo species on mMST (mMST tests only).

Table 2-3. Molar Concentrations of Sorbates, Glycolate, and Peroxo Groups on mMST.

\begin{tabular}{|c|c|c|}
\hline & $\mathbf{5 0 0 0} \mathbf{~ p p m ~ G l y c o l a t e ~ T e s t s}$ & $\mathbf{1 0 0 0 0} \mathbf{~ p p m ~ G l y c o l a t e ~ T e s t s}$ \\
\hline $\mathbf{S r}$ & $6.85 \times 10^{-6} \mathrm{M}$ & $6.85 \times 10^{-6} \mathrm{M}$ \\
\hline $\mathbf{P u}$ & $9.20 \times 10^{-7} \mathrm{M}$ & $9.20 \times 10^{-7} \mathrm{M}$ \\
\hline $\mathbf{N p}$ & $1.94 \times 10^{-6} \mathrm{M}$ & $1.94 \times 10^{-6} \mathrm{M}$ \\
\hline $\mathbf{U}$ & $4.50 \times 10^{-5} \mathrm{M}$ & $4.50 \times 10^{-5} \mathrm{M}$ \\
\hline Glycolate & $6.66 \times 10^{-2} \mathrm{M}$ & $1.33 \times 10^{-1} \mathrm{M}$ \\
\hline Peroxo Groups (mMST tests only) & $6.42 \times 10^{-4} \mathrm{M}$ & $6.42 \times 10^{-4} \mathrm{M}$ \\
\hline
\end{tabular}

Each set of 5 tests consisted of a control bottle (no sorbent), two bottles containing MST (duplicate tests) and two bottles containing mMST (duplicate tests). The control bottle was sampled at each sampling event to monitor for any changes in sorbate concentration due to precipitation or sorption by the polyethylene bottle. MST and mMST were added to the appropriate bottles at concentrations of $0.4 \mathrm{~g} / \mathrm{L}$ and $0.2 \mathrm{~g} / \mathrm{L}$, respectively. After adding the sorbents, the bottles were placed in a shaker-oven, maintained at an average temperature of $27.0 \pm$ $1.1{ }^{\circ} \mathrm{C}$ for tests $1-15$, and $25.8 \pm 1.2{ }^{\circ} \mathrm{C}$ for tests $16-20$. The target temperature for both sets of tests was $25^{\circ} \mathrm{C}$; however, heat from the shaker motor make maintaining this temperature difficult. The bottles were continually shaken at $175 \mathrm{rpm}$ for the duration of the test. Samples were removed at times of $6,12,24$, and 168 hours. At each sampling event, the bottle was removed from the oven and manually shaken for 30 seconds to ensure the solids were homogeneously suspended. A sample was then removed and filtered through a $0.1-\mu \mathrm{m}$ polyvinylidene fluoride (PVDF) syringe filter to remove the solids. An aliquot of the filtrate was acidified with an equal volume of $5 \mathrm{M}$ nitric acid and submitted for inductively coupled plasma - mass spectroscopy (ICP-MS), gamma scan, and plutonium thenoyltrifluoroacetone scintillation (PuTTA) analyses.

\subsection{ESS Tests}

For each ESS test, the researchers used a nominal starting volume of $120 \mathrm{~mL}$ of aqueous salt simulant and $40 \mathrm{~mL}$ of fresh, unused solvent (S2-D1-YESBOB-T-WI). ${ }^{\Upsilon}$ The test protocol is the same one used in all MCU feed qualification work. ${ }^{8}$

The ESS test sequence involves vigorously contacting the cesium loaded aqueous phase with fresh, unused CSSX solvent, in a 3:1 aqueous:organic volume phase ratio. The aqueous phase is then removed, and the remaining organic phase is contacted in turn, with scrub acid $(0.05 \mathrm{M}$ $\left.\mathrm{HNO}_{3}\right)$ twice and strip acid $\left(0.001 \mathrm{M} \mathrm{HNO}_{3}\right)$ three times. In each case, the time of contact is 24 hours and, except for the initial contact, the aqueous:organic volume phase ratio is 1:5. After the 24 hour contact period, the aqueous phase is removed. During each step, samples of each phase

${ }^{\Upsilon}$ This batch of solvent was originally prepared with no extractant as S2-NOBOB-T-WI (see WSRC-NB-2005-00060). The extractant was added later (see WSRC-NB-2007-00054). 
are removed and analyzed for ${ }^{137} \mathrm{Cs}$ content. The resulting D-value is defined as the activity of the ${ }^{137} \mathrm{Cs}$ in the organic phase divided by the ${ }^{137} \mathrm{Cs}$ activity in the aqueous phase. This value is then temperature corrected.

\subsection{Results and Discussion}

\section{1 $\underline{\text { Simulants }}$}

The simulants used for the MST and mMST testing were prepared by spiking a previously prepared simulant with sodium glycolate, targeting final glycolate concentrations of 5,000 and $10,000 \mathrm{ppm}$. After the addition of sodium glycolate, the simulants were equilibrated for 4 days and were then analyzed for soluble glycolate concentration using IC. The measured concentrations came within the $10 \%$ reported analytical uncertainty of the target concentrations, indicating no issues with glycolate solubility in the simulant. The results are provided in Table 3-1.

Table 3-1. Measured Glycolate Concentrations

\begin{tabular}{||c|c|c|c|}
\hline $\begin{array}{c}\text { Glycolate } \\
\text { Concentration }\end{array}$ & $\begin{array}{c}\text { SWS-5-2009 (no } \\
\text { glycolate) }\end{array}$ & $\begin{array}{c}\text { SWS-5-2009 w/5000 } \\
\text { ppm glycolate }\end{array}$ & $\begin{array}{c}\text { SWS-5-2009 w/10000 } \\
\text { ppm glycolate }\end{array}$ \\
\hline Target & $0 \mathrm{ppm}$ & $5000 \mathrm{ppm}$ & $10000 \mathrm{ppm}$ \\
\hline Measured & $<100 \mathrm{ppm}$ & $4790 \mathrm{ppm}$ & $10700 \mathrm{ppm}$ \\
\hline
\end{tabular}

Given the lack of issues in the glycolate spiking in the MST and mMST testing, the glycolate content in the ESS simulants was not measured.

\subsection{MST Performance}

Figures 3-1 through 3-3 show the percent removal for ${ }^{85} \mathrm{Sr}$, $\mathrm{Pu}$, and $\mathrm{Np}$ as a function of contact time for sorption tests performed with MST in simulants with glycolate concentrations of $0 \mathrm{ppm}$, $5000 \mathrm{ppm}$, and $10000 \mathrm{ppm}$ (both in solution and pre-contacted with the MST). The data presented in these plots are the average of the duplicate trials, with the error bars representing 2 standard deviations. Plots of the concentrations versus time and tables summarizing the DFs are provided in Appendix B. The presence of glycolate has the most significant adverse effect on $\mathrm{Sr}$ removal by MST. The impact is a kinetic effect, where the removal of ${ }^{85} \mathrm{Sr}$ is inhibited in the presence of glycolate. After 1 week of contact the percent removed is the same within error; however, at the earlier time points, there is less removal in the presence of either 5000 or 10000 ppm glycolate. The Pu removal kinetics also appear to be slowed in the presence of $10000 \mathrm{ppm}$ glycolate. The percent removal values at 6 and 12 hours are lower in the $10000 \mathrm{ppm}$ glycolate, compared to the 0 and $5000 \mathrm{ppm}$ glycolate simulants. There is no measurable impact to the $\mathrm{Pu}$ removal in the presence of $5000 \mathrm{ppm}$ glycolate. At the later time points, 24 and $168 \mathrm{~h}$, the percent removal is the same across all glycolate concentrations. The pre-contacting of glycolate with the MST did not appear to have a noticeable effect on the $\mathrm{Sr}$ and $\mathrm{Pu}$ removal performance when compared to tests having the same concentration of glycolate in the simulant.

In contrast to the ${ }^{85} \mathrm{Sr}$ and $\mathrm{Pu}$ results, the presence of glycolate resulted in an increase in the removal of Np with MST when compared to the simulant without glycolate. Higher removal was seen in the $5000 \mathrm{ppm}$ glycolate solution when compared to the $10000 \mathrm{ppm}$ glycolate solutions; however, the presence of $10000 \mathrm{ppm}$ glycolate still resulted in greater $\mathrm{Np}$ removal compared to the absence of glycolate. Again, the effect of glycolate appears to be a kinetic effect, in this case the presence of glycolate is increasing the Np removal rate. The pre-contacting of glycolate with the MST slowed the removal of Np compared when compared to tests having the same 
concentration of glycolate in the simulant. The presence of glycolate had no measurable effect on the removal of $U$ by MST.

The fact that the $\mathrm{Np}$ removal was accelerated in the presence of glycolate while the $\mathrm{Sr}$ and $\mathrm{Pu}$ removal was inhibited suggests differing mechanisms for the different species. Based on these results it is not likely that surface fouling of the MST is the responsible mechanism for the decrease in $\mathrm{Sr} \mathrm{DF}$, as one would expect all sorbates to be impacted in that case. A decrease in $\mathrm{Sr}$ removal rate is not unexpected since calculations suggest that glycolate can complex $\mathrm{Sr}^{2+}$ to a limited degree under alkaline conditions (see Appendix A, Figure A-4). Glycolate-complexed strontium would be expected to be less likely to be adsorbed by MST than the free $\mathrm{Sr}^{2+}$. Calculations (provided in Appendix A) suggest that minimal complexation of the actinides occurs in strongly alkaline solutions. However, some degree of complexation is suggested since we observe slower removal of plutonium in the presence of glycolate. We do not have an explanation for the enhanced rate of neptunium removal in the presence of glycolate.

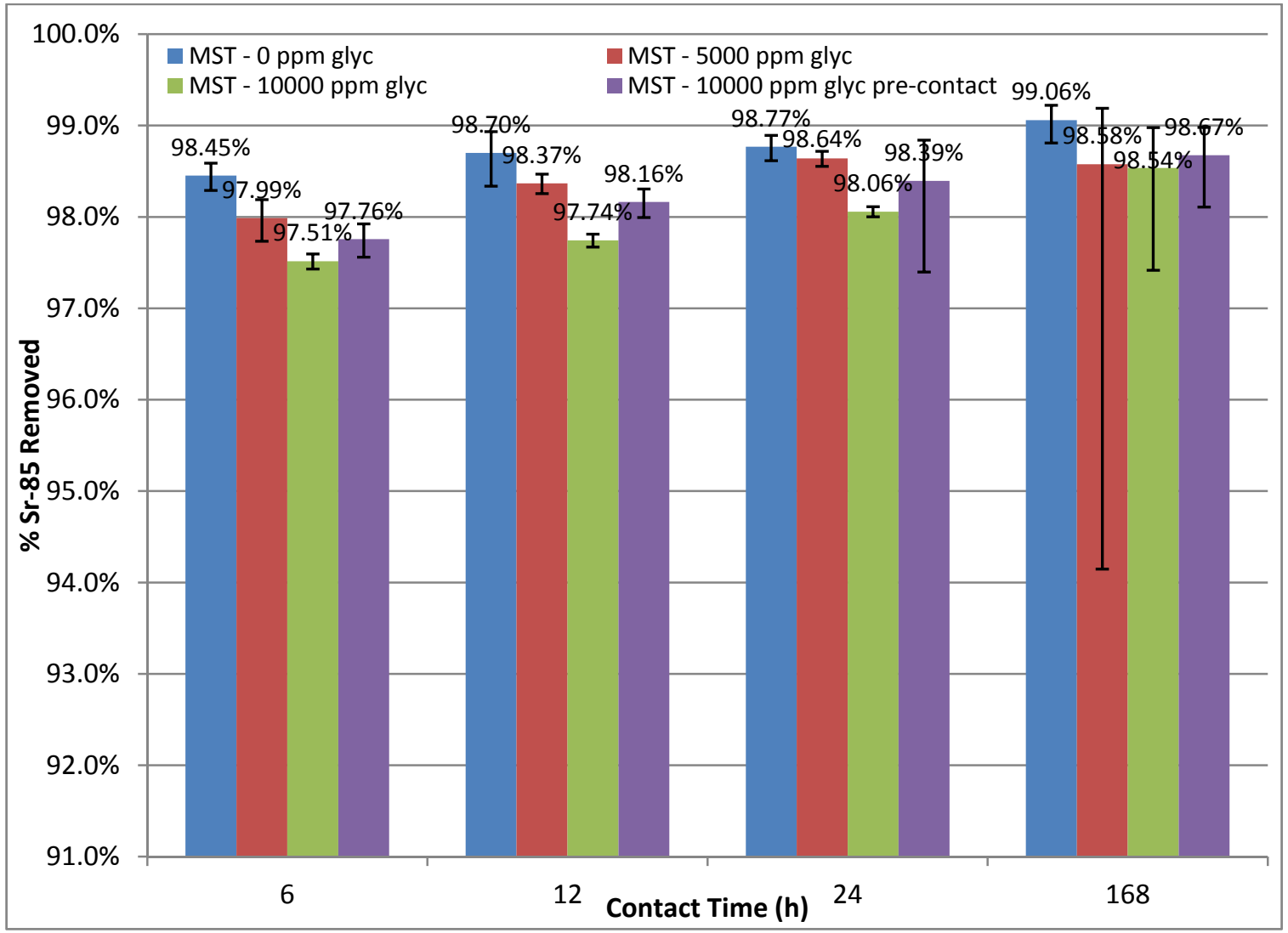

Figure 3-1. Percentage of ${ }^{85} \mathrm{Sr}$ removed versus contact time with MST in the presence of 0 ppm (blue), $5000 \mathrm{ppm}$ (red), and $10000 \mathrm{ppm}$ glycolate in solution (green) or pre-contacted with MST (purple). 


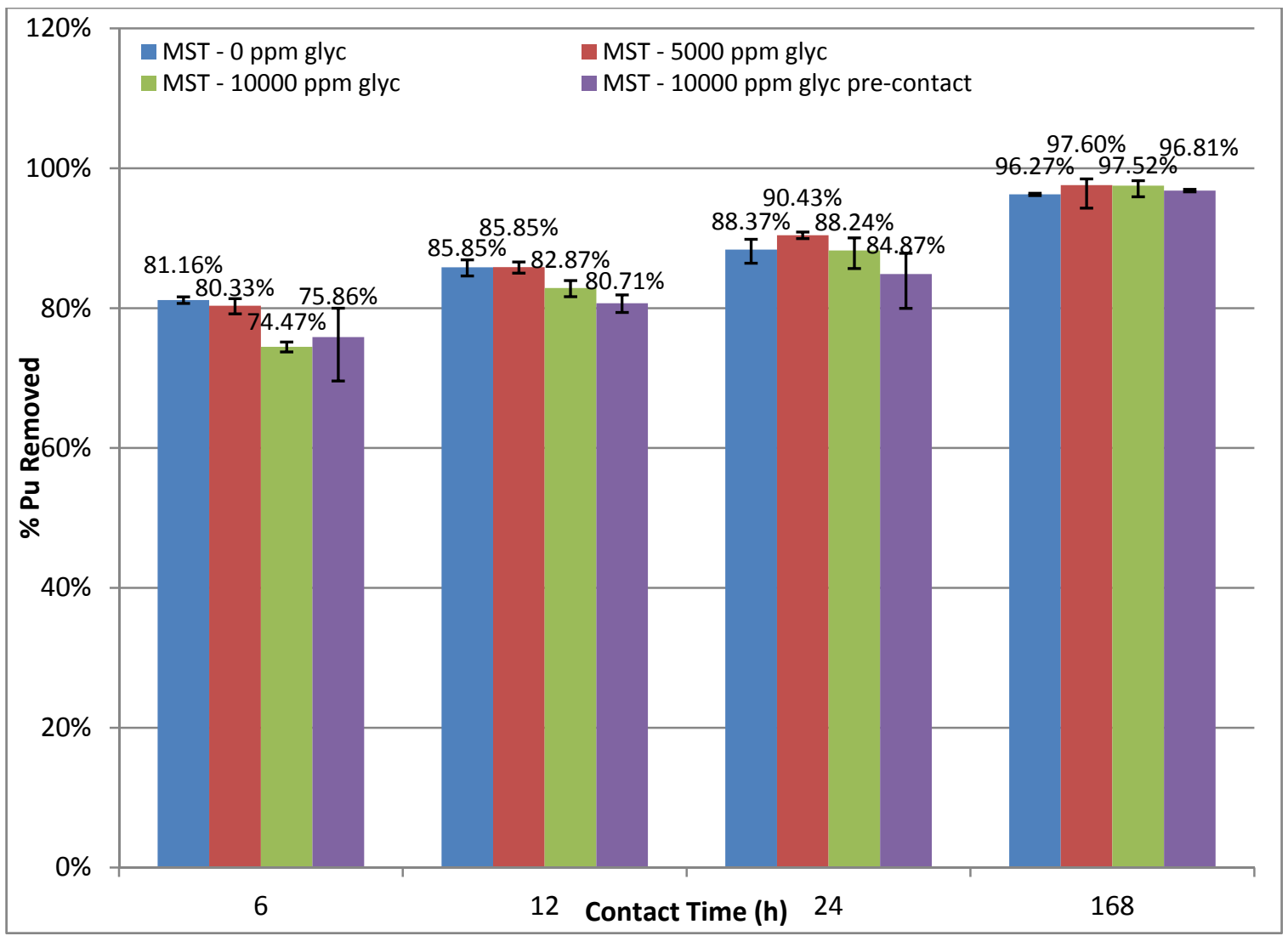

Figure 3-2. Percentage of Pu removed versus contact time with MST in the presence of 0 ppm (blue), 5000 ppm (red), and 10000 ppm glycolate in solution (green) or pre-contacted with MST (purple). 


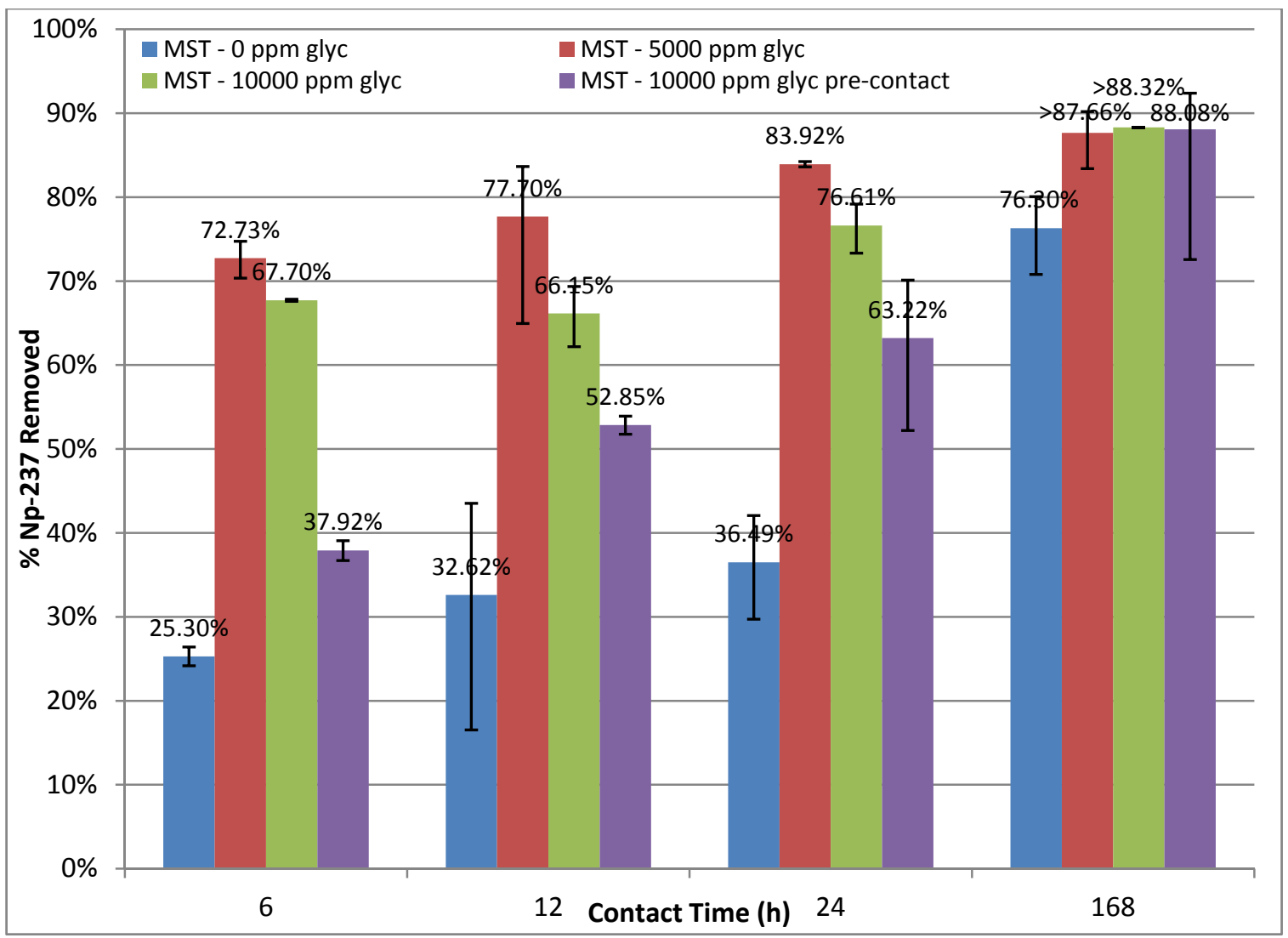

Figure 3-3. Percentage of Np removed versus contact time with MST in the presence of 0 ppm (blue), 5000 ppm (red), and 10000 ppm glycolate in solution (green) or pre-contacted with MST (purple).

\section{3 mMST Performance}

Figures 3-6 through 3-8 show the percent removal of ${ }^{85} \mathrm{Sr}, \mathrm{Pu}$, and $\mathrm{Np}$ as a function of time for sorption tests performed with mMST in simulants with glycolate concentrations of $0 \mathrm{ppm}, 5000$ ppm, and $10000 \mathrm{ppm}$ (both in solution and pre-contacted with the mMST). Plots of the concentrations versus time and tables summarizing the DFs are provided in Appendix B. In contrast to what was observed with MST, the presence of glycolate appears to slow the removal of all three sorbates by mMST.

In the case of ${ }^{85} \mathrm{Sr}$, at the $6-24$ hour time points the percentage of ${ }^{85} \mathrm{Sr}$ removed is lower in the presence of either 5000 or 10000 ppm glycolate compared to the glycolate free simulant; however, by the 168 hour time point there is overlap of the error bars for all three glycolate concentrations. There was a much larger spread in the $\mathrm{Np}$ data between the duplicate trials, resulting in larger error bars making comparison more difficult. However, the presence of glycolate appears to also slow the removal of $\mathrm{Np}$. There is some overlap of the $0 \mathrm{ppm}$ and $5000 \mathrm{ppm}$ data at all the time points, except for 24 hours. The $10000 \mathrm{ppm}$ samples are consistently lower than the data in the absence of glycolate; however, by 168 hours the $10000 \mathrm{ppm}$ glycolate solution has reached the percent removal achieved in the $0 \mathrm{ppm}$ glycolate solution at 6 hours, indicating a kinetic effect, rather than reduced capacity of the material.

The effects were less pronounced for $\mathrm{Pu}$. There is no measurable decrease in $\mathrm{Pu}$ removal in the presence of $5000 \mathrm{ppm}$ glycolate compared to the glycolate free simulant. There is a small 
decrease in the percentage of $\mathrm{Pu}$ removed in the presence of $10000 \mathrm{ppm}$ glycolate through 24 hours; however, at the 168-h time point the Pu concentration is below the method detection limit for all three glycolate concentrations, resulting in greater than values for the percent removed. The presence of glycolate did not change the lack of affinity of mMST for U.

Even though the glycolate had a greater impact on the mMST performance, the material still outperforms the baseline MST for Sr and Pu removal. Even in the presence of $10000 \mathrm{ppm}$ glycolate the $\mathrm{Pu} \mathrm{DF}$ for mMST is still much greater than that of MST, and for ${ }^{85} \mathrm{Sr}$, the 168 -h DF for mMST in the presence of $10000 \mathrm{ppm}$ glycolate was similar to the DF for MST in the absence of glycolate. For Np, the mMST $6-24$ hour DFs in the presence of $10000 \mathrm{ppm}$ glycolate were similar to the MST DFs in the absence of glycolate. The 168 -h Np DF for mMST was about $40 \%$ of the MST 168-h Np DF. As with MST, the pre-contacting of glycolate with the mMST did not appear to have a significant effect on the performance when compared to tests having the same concentration of glycolate in the simulant. Based on these findings, we conclude that the presence of 5,000 and 10,000 ppm glycolate slows removal by complexing the sorbates to a limited degree and not by depositing or forming a film on the surface of the mMST.

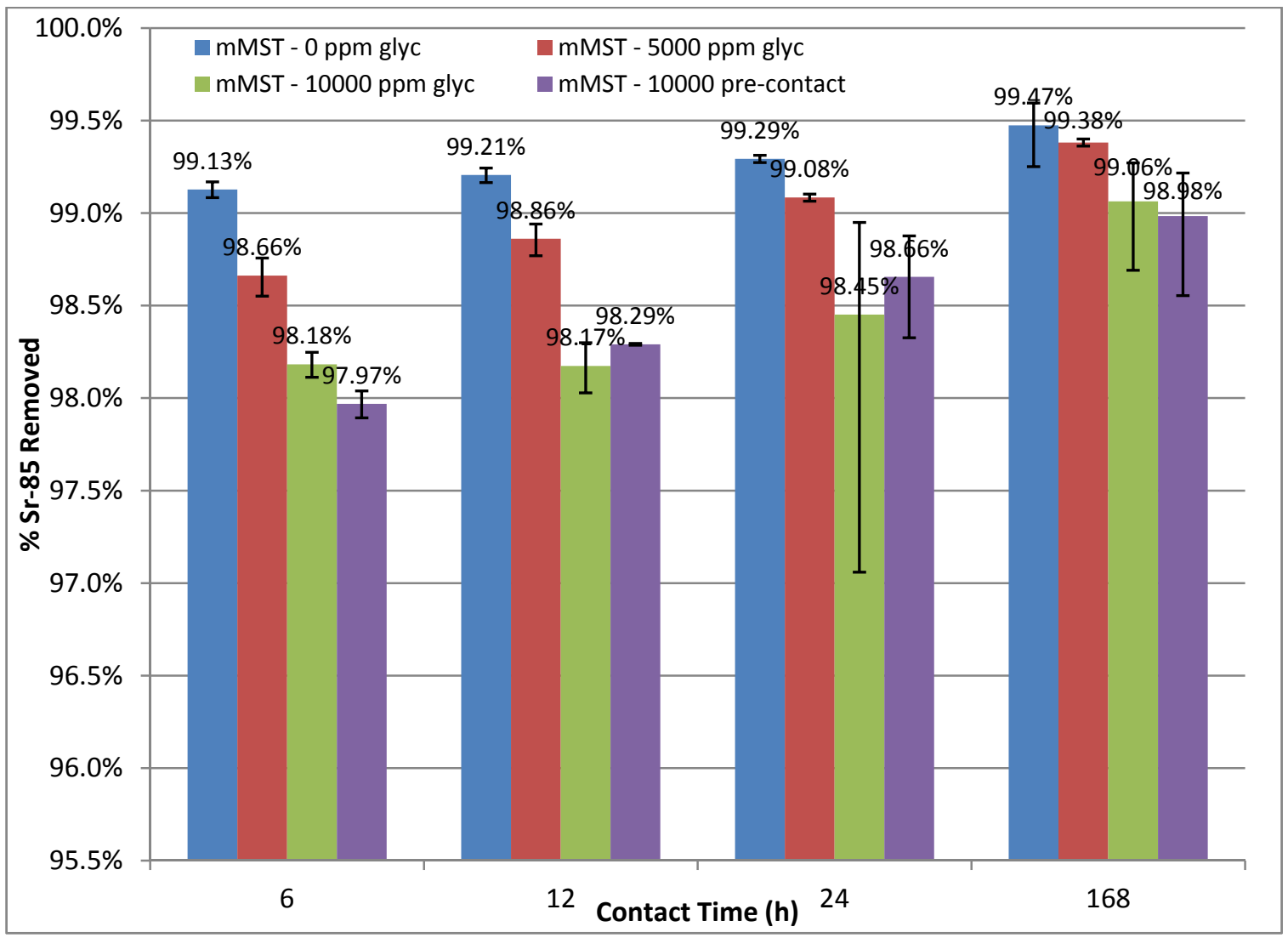

Figure 3-4. Percentage of ${ }^{85} \mathrm{Sr}$ removed versus contact time with mMST in the presence of 0 ppm (blue), 5000 ppm (red), and 10000 ppm glycolate in solution (green) or pre-contacted with mMST (purple). 


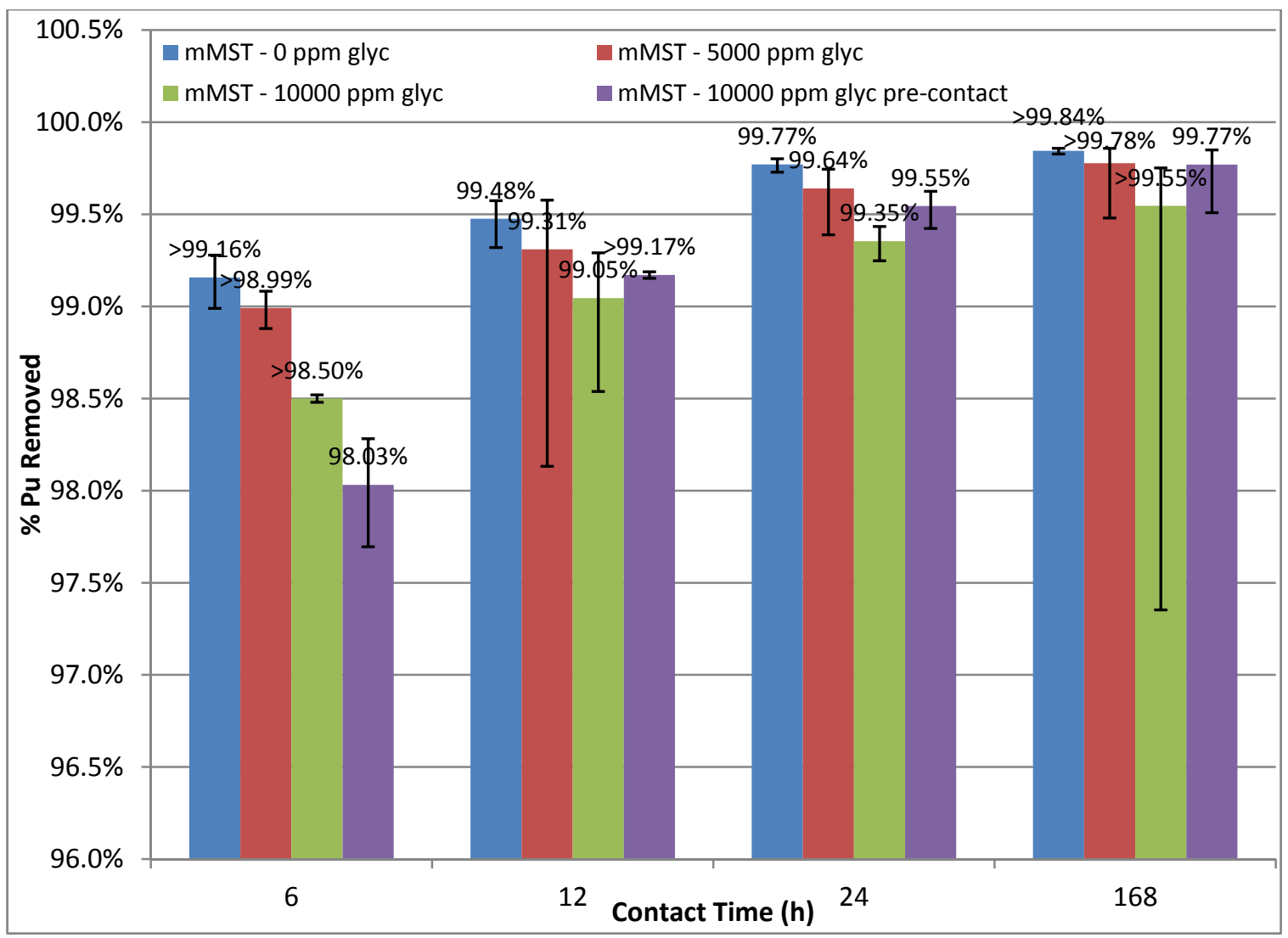

Figure 3-5. Percentage of Pu removed versus contact time with mMST in the presence of 0 ppm (blue), 5000 ppm (red), and 10000 ppm glycolate in solution (green) or pre-contacted with mMST (purple). 


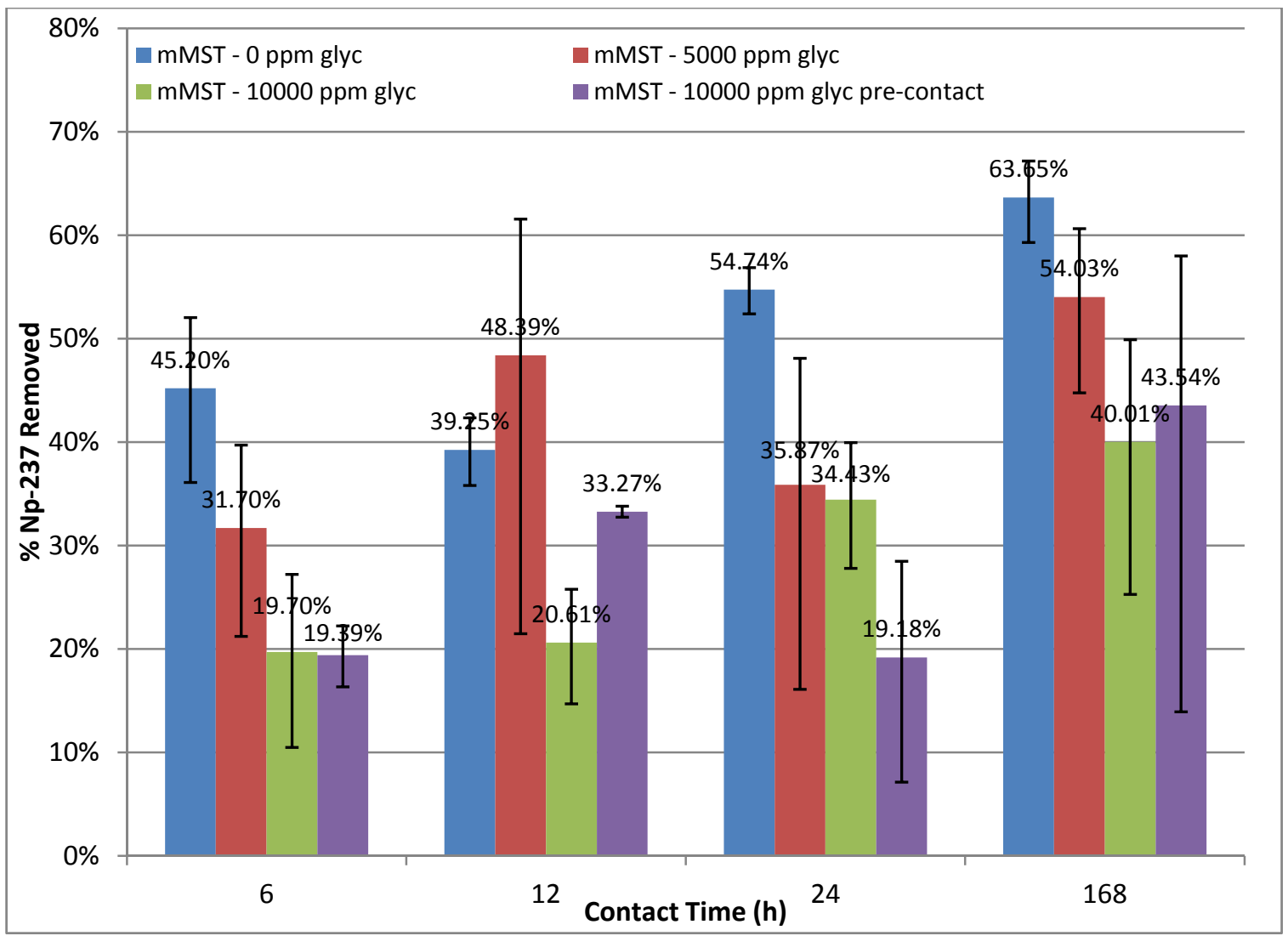

Figure 3-6. Percentage of Np removed versus contact time with mMST in the presence of 0 ppm (blue), 5000 ppm (red), and 10000 ppm glycolate in solution (green) or pre-contacted with mMST (purple).

\subsection{Glycolate Effects on Cesium Removal}

Table 3-2 shows the results from the ESS Tests, corrected to the normal process operating temperatures (i.e., $23{ }^{\circ} \mathrm{C}$ for extraction and $33{ }^{\circ} \mathrm{C}$ for scrubbing and stripping).

Table 3-2. Cesium Distribution Values for the ESS Tests

\begin{tabular}{||c|c|c|c|c|c|c||}
\hline Material & Extraction & Scrub \#1 & Scrub \#2 & Strip \#1 & Strip \#2 & Strip \#3 \\
\hline $\begin{array}{c}\text { Reference Case } \\
\text { (Expected Values) }\end{array}$ & $>8$ & $>0.6,<2$ & $>0.6,<2$ & $<0.2$ & $<0.16$ & $<0.16$ \\
\hline 0 ppm glycolate & 19.3 & 2.23 & 1.47 & 0.0350 & 0.0270 & 0.0294 \\
\hline $\mathbf{5 , 0 0 0}$ ppm glycolate & 148 & 1.93 & 1.79 & 0.0390 & 0.0240 & $<0.0194$ \\
\hline $\mathbf{1 0 , 0 0 0 ~ p p m ~ g l y c o l a t e ~}$ & 18.8 & 1.80 & 1.65 & 0.0470 & 0.0216 & $<0.0223$ \\
\hline
\end{tabular}

All three tests gave acceptable values for all steps, with the exception of Scrub \#1 for the $0 \mathrm{ppm}$ test (blank). The slight deviation from the acceptable range is commonly seen and is not considered to be problematic.

From the bulk chemistry of the solutions, an extraction DF of $\sim 17.1$ is predicted. ${ }^{9}$ 
In the 5,000 ppm test, the Extraction \#1 test point gave a result that is clearly impossible. Through the use of variable sensitivity analysis, SRNL believes that this value is due to an unanticipated dilution in the aqueous Extraction \#1 analytical sample. Sample reanalysis is underway to confirm this hypothesis. Nevertheless, even with this unresolved data, there is no indication that the presence of 5,000 ppm of glycolate affects the cesium removal behavior.

Although not tested, the impact of glycolate for the Next Generation Solvent - that replaces BOBCalixC6 with MaxCalix - is expected to be very similar to that for the baseline solvent. Testing is needed to confirm.

\subsection{Conclusions}

The presence of glycolate was found to impact the sorption kinetics of both MST and mMST. For MST, the presence of glycolate slowed the removal of both $\mathrm{Sr}$ and $\mathrm{Pu}$, while increasing the removal rate of $\mathrm{Np}$. Pre-contacting the MST with glycolate resulted in similar performance as when glycolate was simply present in the simulant.

In the case of mMST, glycolate was found to decrease the removal rates of all three sorbates ( $\mathrm{Sr}$, $\mathrm{Pu}$, and $\mathrm{Np}$ ). However, even in the presence of $10,000 \mathrm{ppm}$ glycolate the mMST outperforms the baseline MST in the absence of glycolate for Pu removal, and has comparable ${ }^{85} \mathrm{Sr}$ removal to MST in the absence of glycolate. As with MST, the pre-contacting of glycolate with the mMST did not appear to have a significant effect on the performance when compared to tests having the same concentration of glycolate in the simulant. Based on these results it is likely that glycolate is impacting the removal rates by forming complexes with the sorbates, and not by fouling the MST or mMST surface.

The impact on DF measured in this report is for a single batch contact. Facility operations involve accumulation of multiple batches of MST. As a result, DF in the facility operations is not directly correlated with the single batch contact values and historically is superior to the laboratory test data. Rather than experimentally assessing the impact of multiple batches, a more practical and cost effective approach is to add glycolate impact to the salt batch qualification program for future batches after the program makes a final selection of process quantities and a better understanding of carryover from DWPF melter operations is known.

From the cesium mass transfer test results, we can discern no negative effect of glycolate on the cesium removal efficiency. While there is a single anomalous sample result yet to resolve, SRNL does not anticipate this result deviating from the results of the other two tests.

\subsection{Recommendations}

Additional testing is recommended to further examine the nature of the interaction of glycolate with MST and mMST and also to help address some of the pre-mortem risks on ARP/MCU operations with implementation of the glycolate flowsheet. Specifically, we propose the following:

1. Use of FTIR and Raman spectroscopy to examine the surface of the MST and mMST particles to determine if glycolate is adhering to the surface. These measurements will help to determine if surface fouling is responsible for the decreased performance seen in the presence of glycolate.

2. Iodometric titrations to determine the peroxide content in the mMST before and after exposure to glycolate. This will allow us to determine if the glycolate is reacting with the peroxide groups on the mMST, thereby reducing the performance of the material. 
3. Particle size measurements of the MST and mMST from the experiments performed with glycolate to determine if glycolate is causing the particles to agglomerate.

4. Inductively couples plasma - emission spectroscopy (ICP-ES) analysis of the supernate from these experiments to measure the soluble Ti concentration to determine if glycolate is causing increased leaching of Ti from MST and mMST.

5. Material compatibility evaluations to ensure that glycolate does not negatively affect the physical properties of the various polymers used at MCU.

6. Performance of dispersion tests with the glycolate spiked solutions to ensure there is no hydraulic effect on the cesium removal performance.

7. ESS testing to confirm there is no impact to the Next Generation Solvent.

In addition to those recommendations, we also advise that further testing be performed if the glycolate concentration exceeds $10,000 \mathrm{ppm}$ in the DWPF recycle stream. 
SRNL-STI-2012-00218

Revision 0

\subsection{References}

${ }^{1}$ T. Wagnon, "Defense Waste Processing Facility - Alternate Reductant - Systems Engineering Study", G-AES-S-00003, Rev. 0.

${ }^{2}$ T. L. Fellinger, "Nitric/Formic/Glycolic Flowsheet Tasks - Determination of Fe/Pu Solubility and Impact to Solvent Extraction", HLW-DWPF-TTR-2011-025, Rev. 1, August 2011.

${ }^{3}$ K. M. L. Taylor-Pashow, T. B. Peters, and T. C. Shehee, "Task Technical and Quality Assurance Plan for Determining the Impact of Glycolate on ARP/MCU Operations", SRNL-STI2012-00072, Rev. 0, November 2011.

${ }^{4}$ D. T. Hobbs, M. J. Barnes, R. L. Pulmano, K. M. Marshall, T. B. Edwards, M. G. Bronikowski, and S. D. Fink, (2005) "Strontium and Actinide Separations from High Level Nuclear Waste Solutions Using Monosodium Titanate 1. Simulant Testing." Separation Science and Technology, 40 (15): 3093.

${ }^{5}$ M. Nyman and D. T. Hobbs, (2006) "A Family of Peroxo-titanate Materials Tailored for Optimal Strontium and Actinide Sorption.” Chem. Mater. 18 (26): 6425.

${ }^{6}$ D. P. Lambert, "Glycolic-Formic Flowsheet Development Part I", SRNL-NB-2011-00021. Calculation by M. E. Stone using input from "Glycolic - Formic Acid Flowsheet Final Report for Downselection Decision” SRNL-STI-2010-00523, Rev. 1, March 2011.

${ }^{7}$ L. N. Oji, T. L. Fellinger, D. T. Hobbs, N. P. Badheka, W. R. Wilmarth, V. H. Dukes, M. S. Blume, and S. W. McCollum, "Selection of an Inhibitor for the Prevention of Sodium Aluminosilicate Scale in the HLW Evaporators”, WSRC-TR-2007-00381, September 30, 2007.

${ }^{8}$ T. B. Peters and S. D. Fink, "Sample Results from the Integrated Salt Disposition Program Macrobatch 5 Tank 21H Qualification MST, ESS and PODD Samples”, SRNL-STI-2012-00207, April 2012.

${ }^{9}$ K. Adu-Wusu, D. D. Walker, T. B. Edwards, "Waste and Solvent Composition Limits for Modular Caustic-Side Solvent Extraction Unit (MCU)”, WSRC-TR-2005-00258, May 26, 2005. 
SRNL-STI-2012-00218

Revision 0

Appendix A. Glycolate complexation under alkaline conditions 


\section{Complexation Calculations}

\section{Glycolate complexation under alkaline conditions}

Speciation calculations for glycolate complexation with $\mathrm{UO}_{2}{ }^{2+}, \mathrm{NpO}_{2}{ }^{+}, \mathrm{Th}^{4+}$ (used as a 4+ analogue of $\mathrm{Pu}$ ) and $\mathrm{Sr}^{2+}$ have been performed. Stability constants for the metal/glycolate system were selected from the NIST Standard Reference Database. ${ }^{[1]}$ The values were chosen at the highest ionic strengths available that also gave internally consistent data. Typically $\mu=1.0 \mathrm{M}$, with the exception of strontium with $\mu=0.1 \mathrm{M}$. Speciation plots have been prepared using the speciation program HYSS 2009. ${ }^{[2]}$

The plots shown in Figures A-1 through A-4 display the log of the metal concentration vs. $\mathrm{pH}$. The $\mathrm{pH}$ range 2-12 has been chosen for a broader understaning of the system even though the alkaline side is of main interest. The advantage of this display can be found in visuallization of the regions where glycolate will more strongly interact with the metals. Uranyl and $\mathrm{Th}^{4+}$ will be typically found as a hydroxide at $\mathrm{pH}>7$. With neptunyl, this $\mathrm{pH}$ increases slightly to where the hydrolysis product begins to dominate at $\sim \mathrm{pH}=9$. For $\mathrm{Sr}^{2+}$, the free $\mathrm{Sr}^{2+}$ dominates across the $\mathrm{pH}$ range shown with a lower concentration of a 1:1 strontium glycolate complex. At higher $\mathrm{pH}$, the 1:1 hydrolysis product begins to grow in. Based on these plots, it can be concluded that glycolate will not form a complex with the actinides in any appreciable quantities.

[1] Martell, A. E.; Smith, R. M.; Motekaitis, R. J. NIST Standard Reference Database 46, Version 8.0 - NIST Critically Selected Stability Constants of Metal Complexes, 2004.

[2] a) HYSS 2009 b) Hyperquad simulation and speciation (HySS): a utility program for the investigation of equilibria involving soluble and partially soluble species", Coordination Chemistry Reviews, 184 (1999) 311-318.

Table 1. Concentrations of metal and ligand species, of interest in the system, used in speciation calculations.

\begin{tabular}{ccc}
\hline \hline Metal or ligand of interest & ug/L & M \\
\hline $\mathrm{U}$ & 10000 & $4.20 \mathrm{E}-05$ \\
$\mathrm{~Np}$ & 500 & $2.11 \mathrm{E}-06$ \\
$\mathrm{Pu}$ & 200 & $8.37 \mathrm{E}-07$ \\
Total Sr & & $6.85 \mathrm{E}-06$ \\
Total Cs & & $1.40 \mathrm{E}-04$ \\
Gly & & 0.133 \\
\hline \hline
\end{tabular}


SRNL-STI-2012-00218

Revision 0

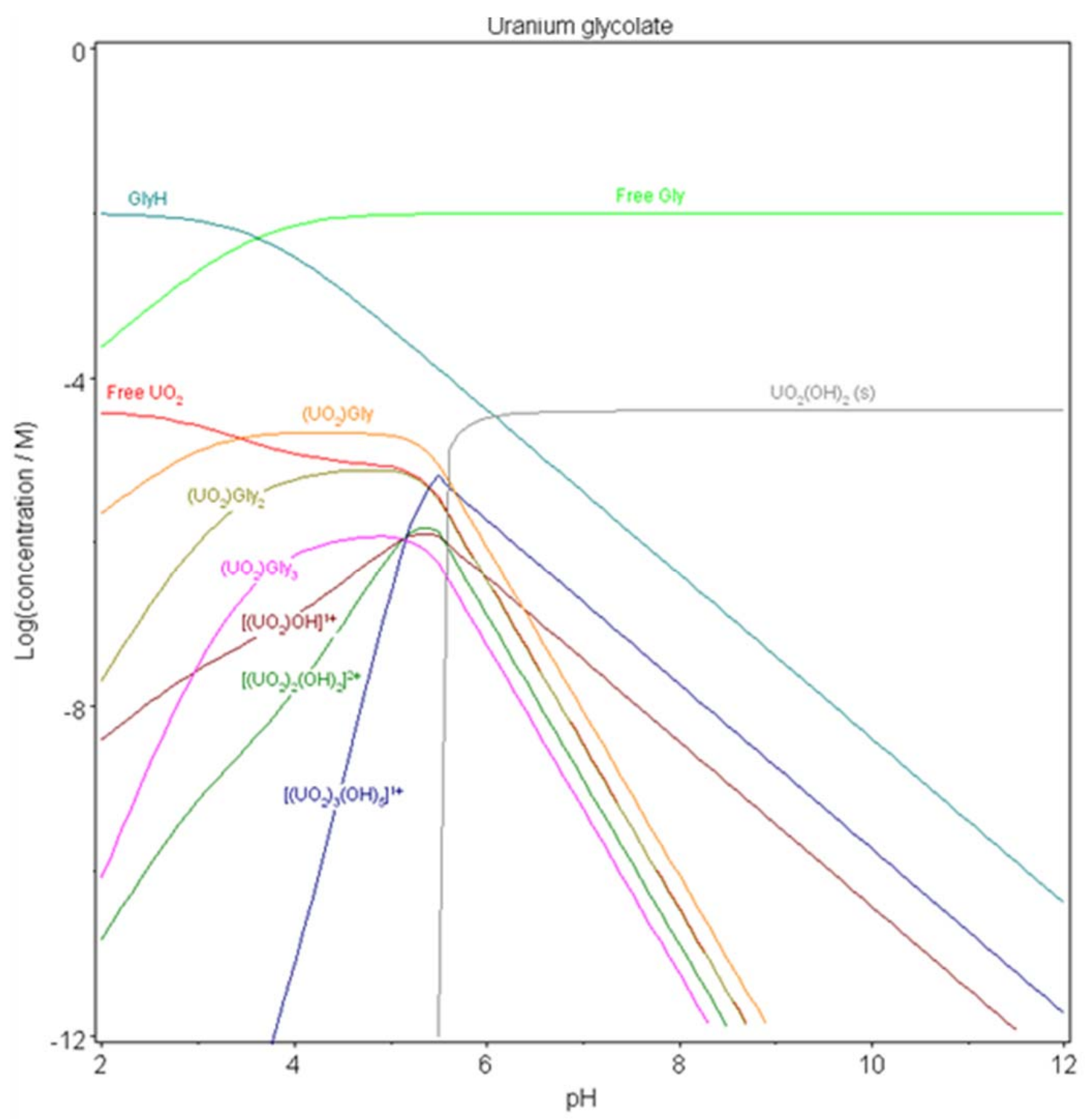

Figure A-1. Speciation plot for uranyl in the presence of glycolate. 
SRNL-STI-2012-00218

Revision 0

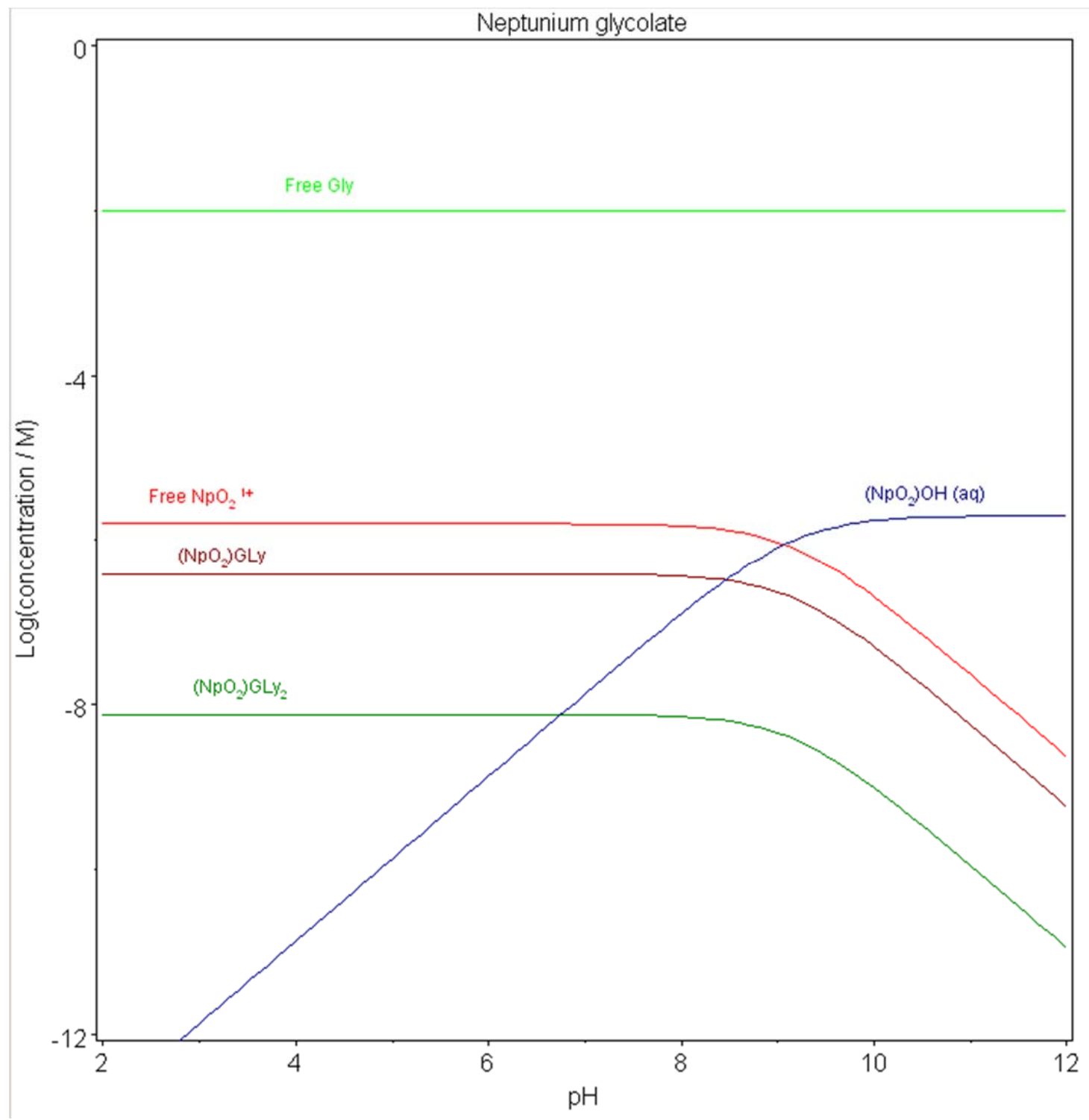

Figure A-2. Speciation plot for neptunyl in the presence of glycolate. 
SRNL-STI-2012-00218

Revision 0

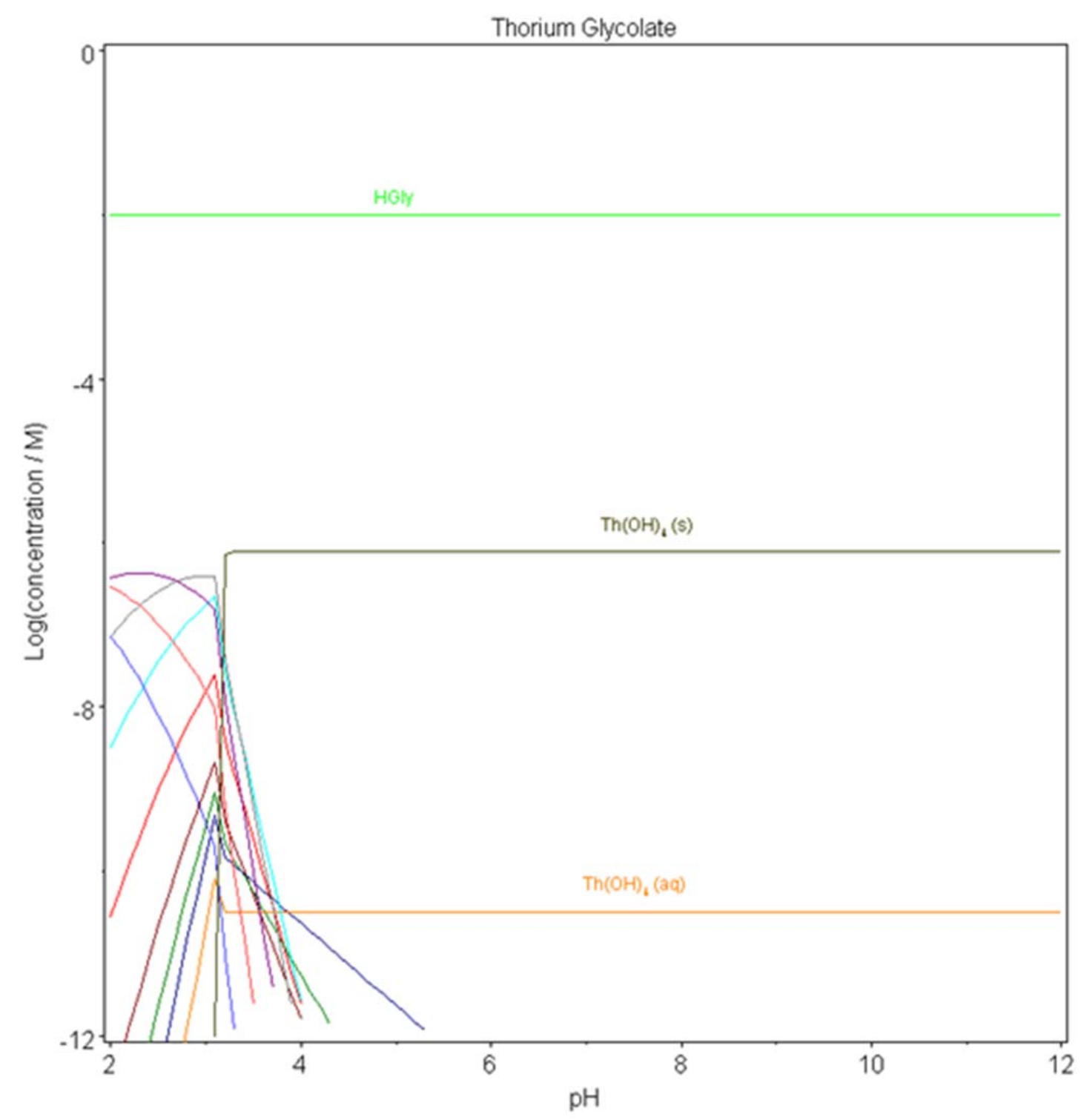

Figure A-3. Speciation plot for $\mathrm{Th}^{4+}$ in the presence of glycolate. 
SRNL-STI-2012-00218

Revision 0

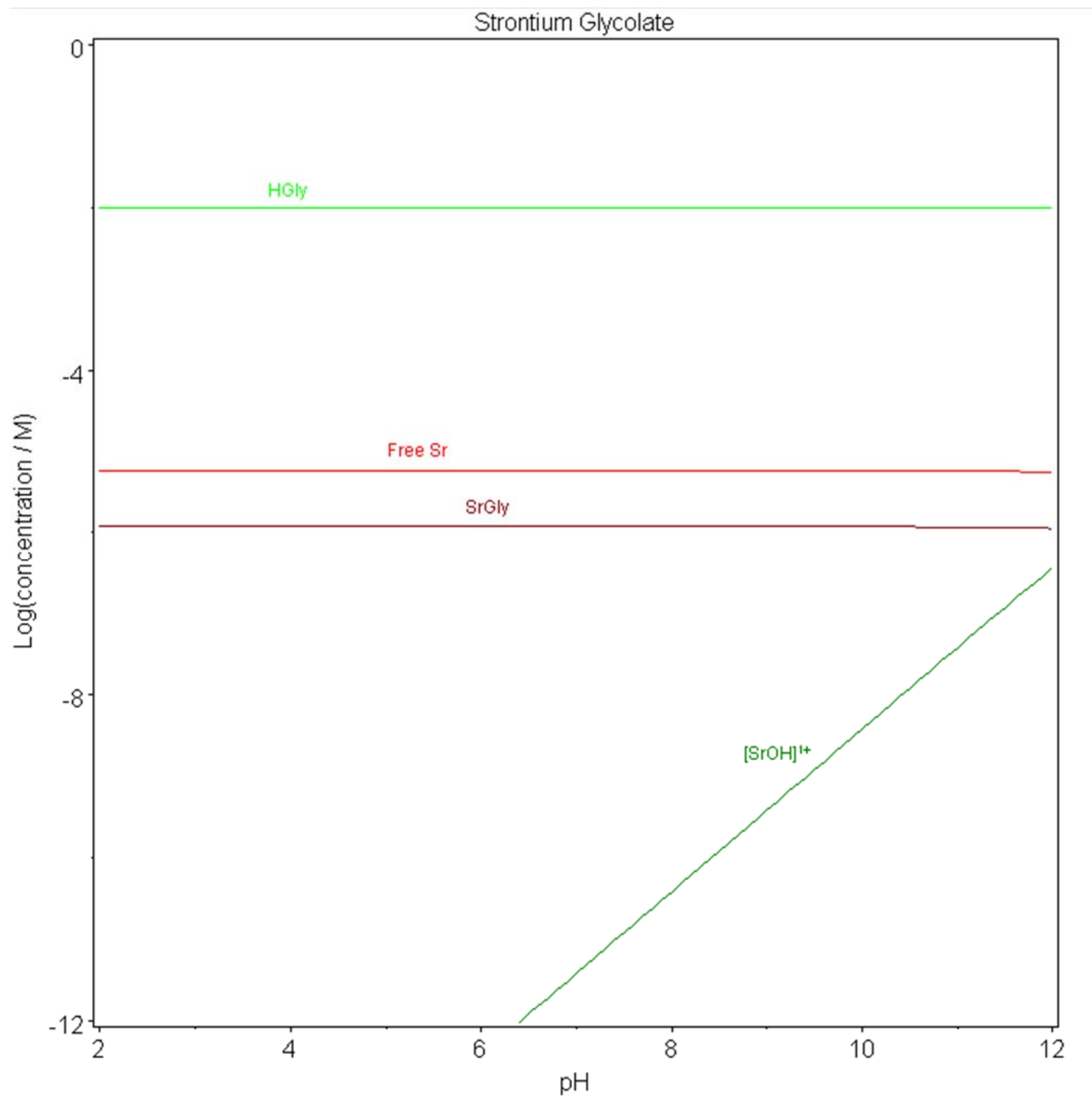

Figure A-4. Speciation plot for $\mathrm{Sr}^{2+}$ in the presence of glycolate. 
SRNL-STI-2012-00218

Revision 0

Appendix B. Additional MST/mMST sorption data 
SRNL-STI-2012-00218

Revision 0

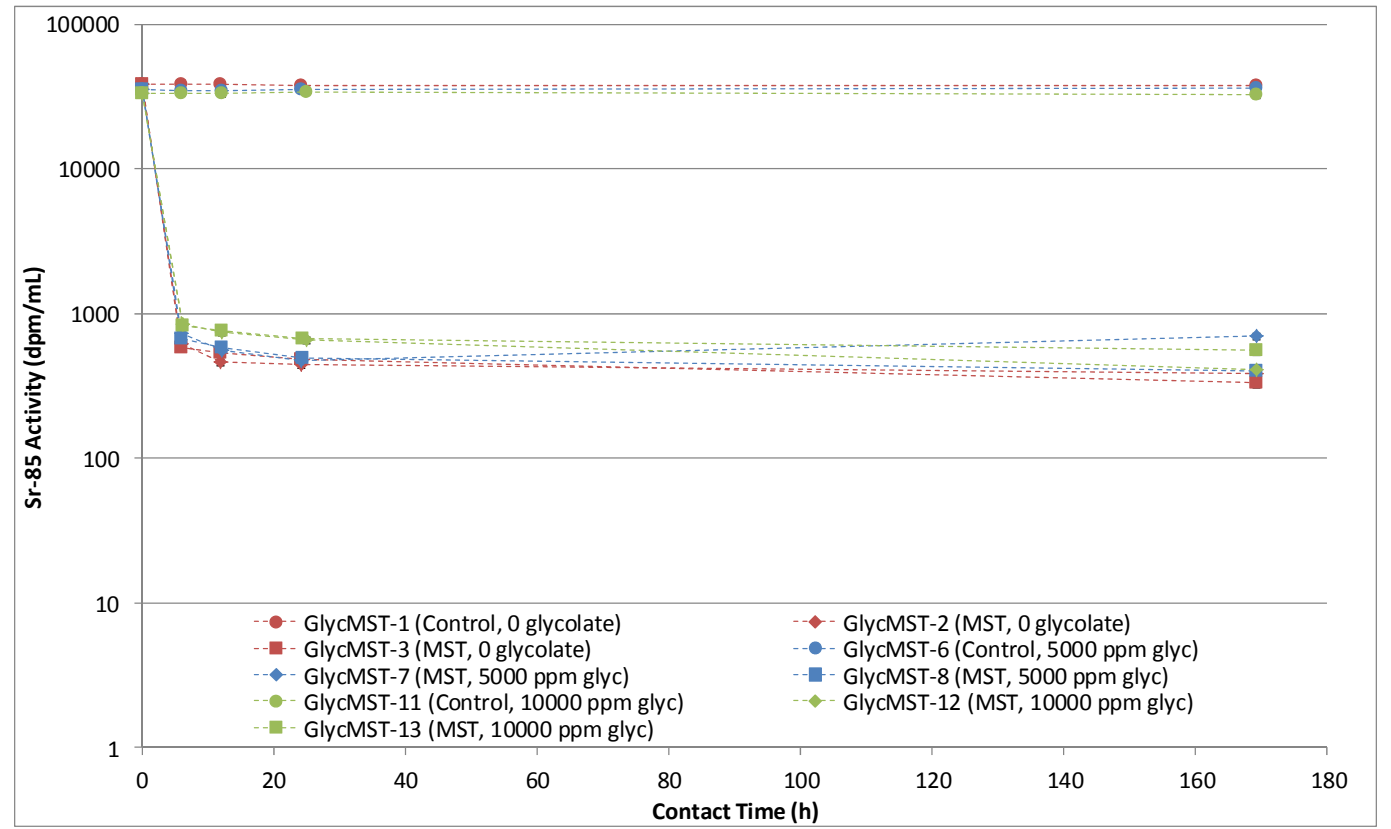

Figure B-1. ${ }^{85} \mathrm{Sr}$ activity versus contact time with MST in the presence of $0 \mathrm{ppm}$ (red), 5000 ppm (blue), or 10000 ppm (green) glycolate.

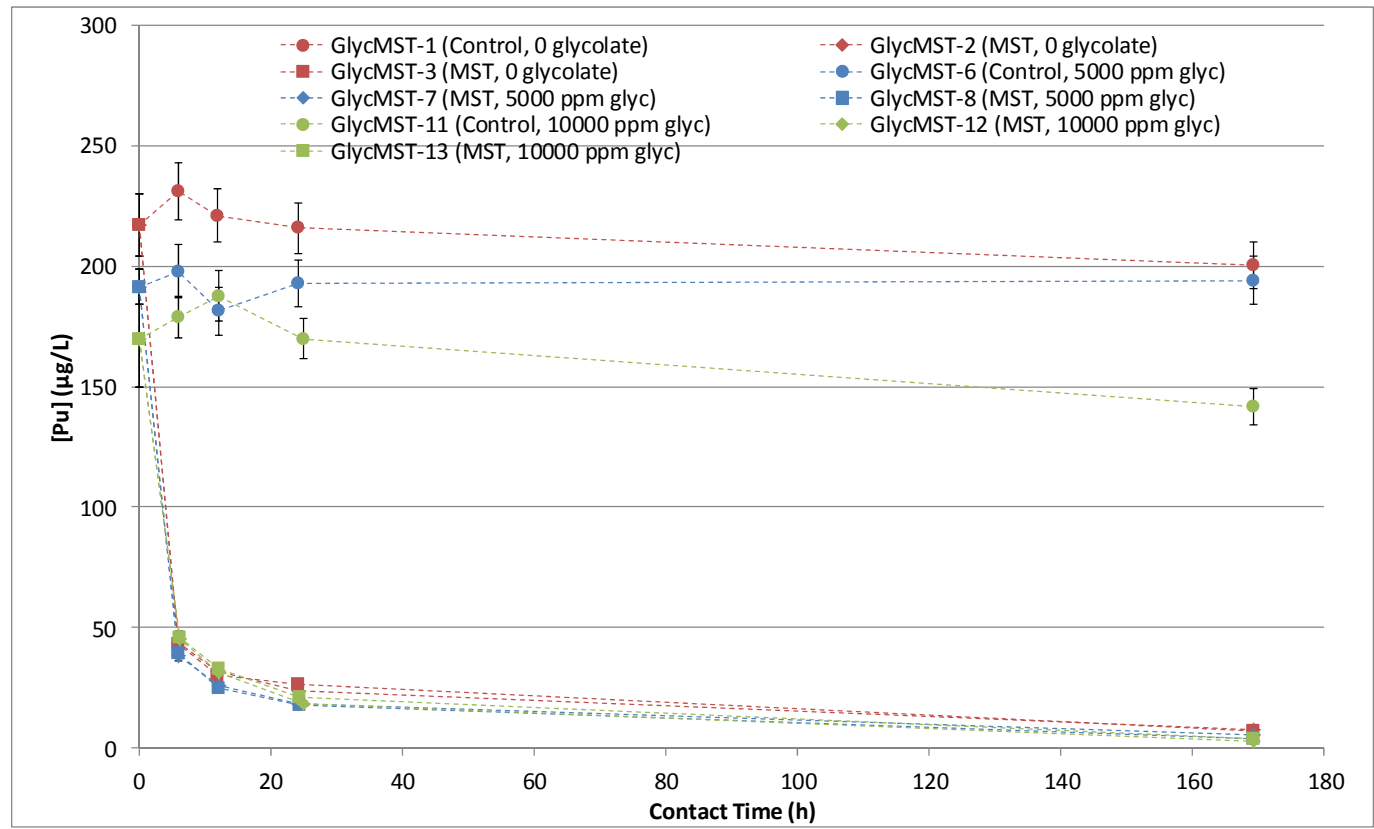

Figure B-2. Pu concentration versus contact time with MST in the presence of $0 \mathrm{ppm}$ (red), 5000 ppm (blue), or 10000 ppm (green) glycolate. 


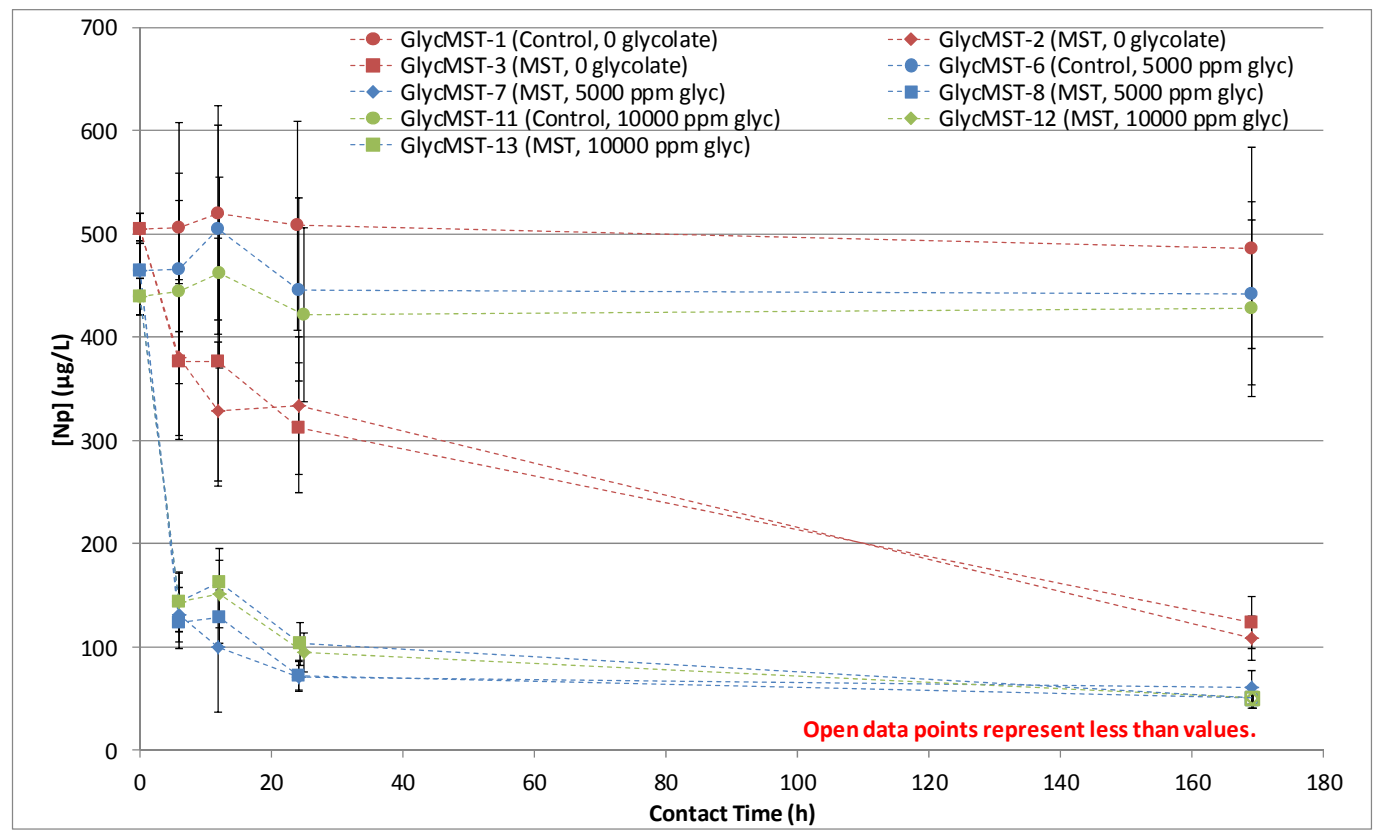

Figure B-3. Np concentration versus contact time with MST in the presence of 0 ppm (red), 5000 ppm (blue), or 10000 ppm (green) glycolate.

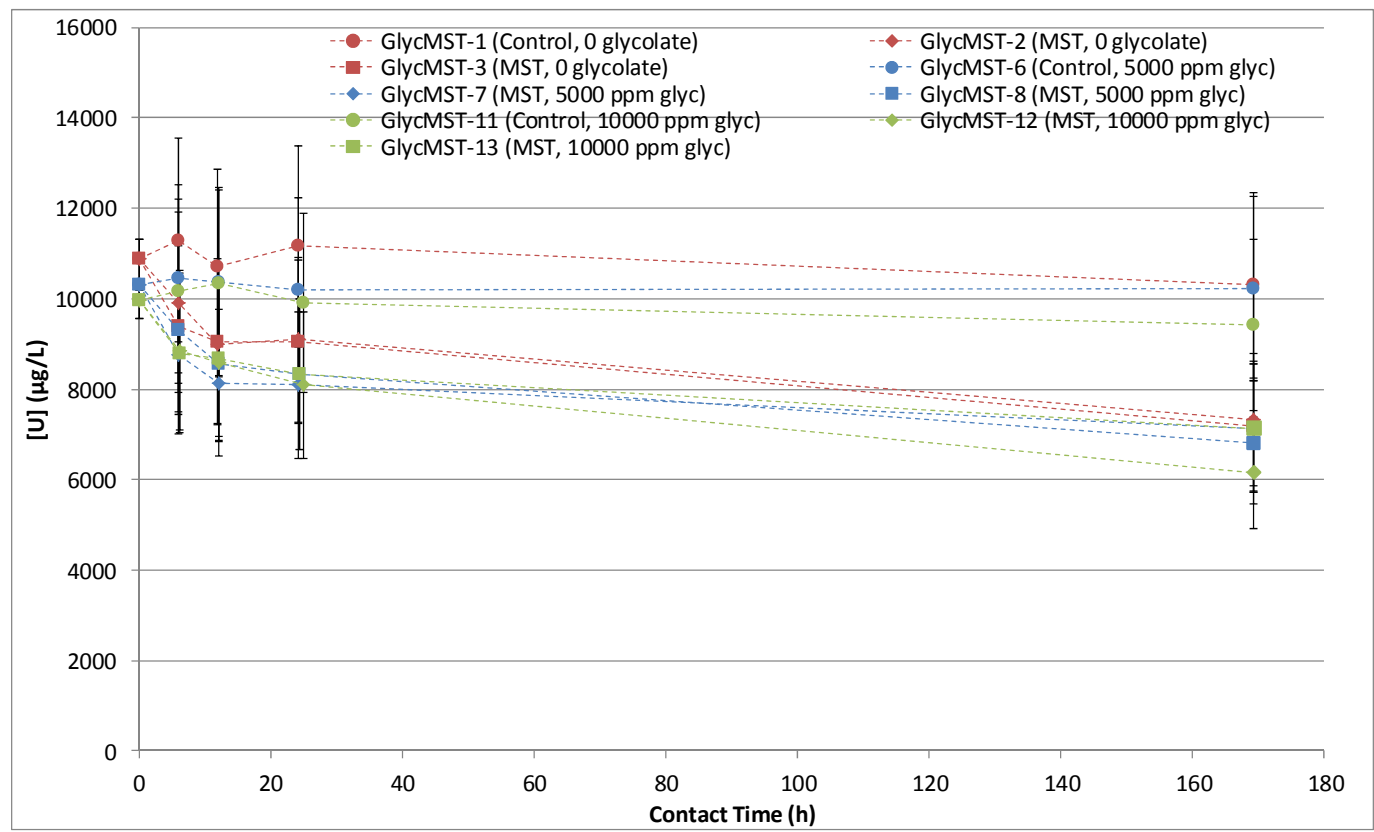

Figure B-4. U concentration versus contact time with MST in the presence of $0 \mathrm{ppm}$ (red), 5000 ppm (blue), or 10000 ppm (green) glycolate. 
SRNL-STI-2012-00218

Revision 0

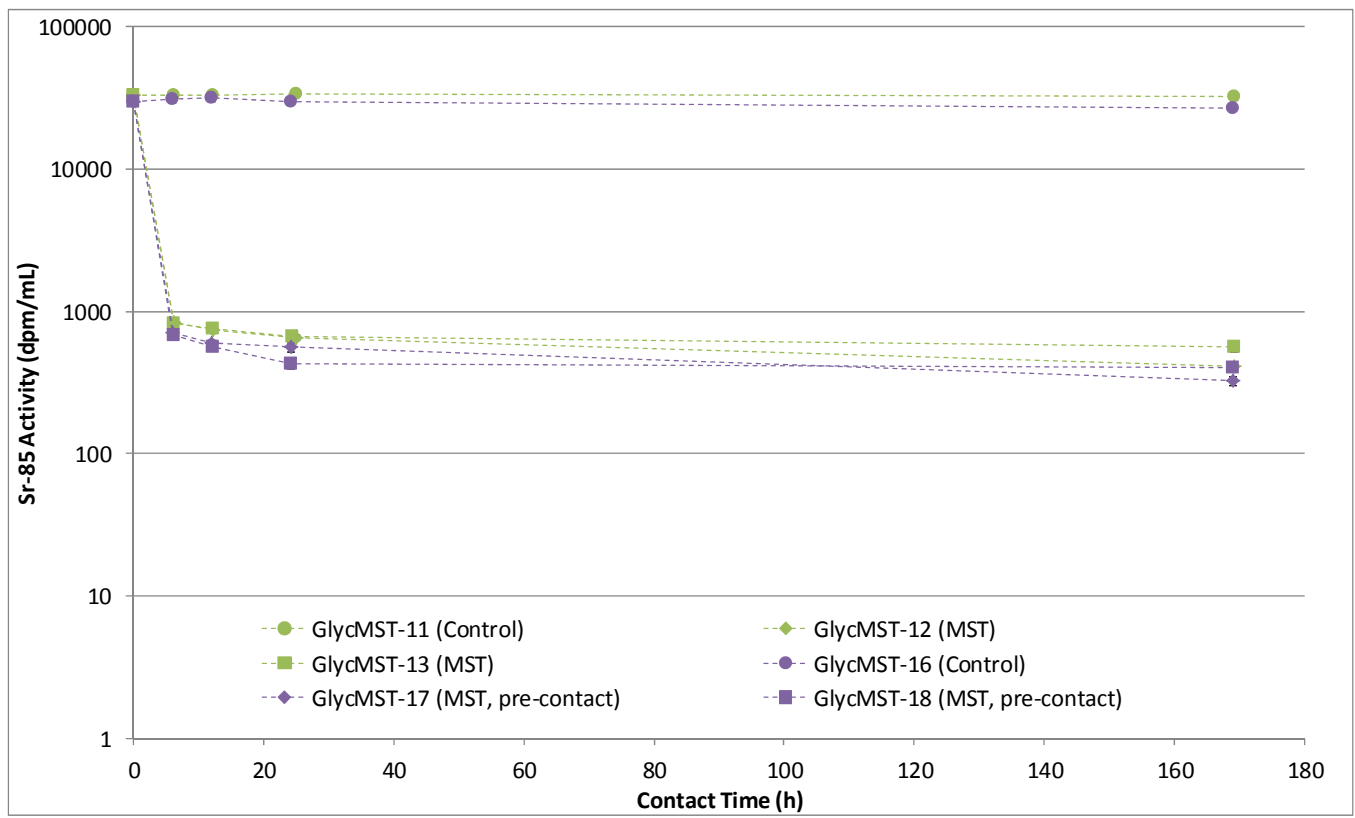

Figure B-5. ${ }^{85} \mathrm{Sr}$ activity versus contact time with MST in the presence of $10000 \mathrm{ppm}$ glycolate with (purple) and without (green) pre-contacting the glycolate with the MST.

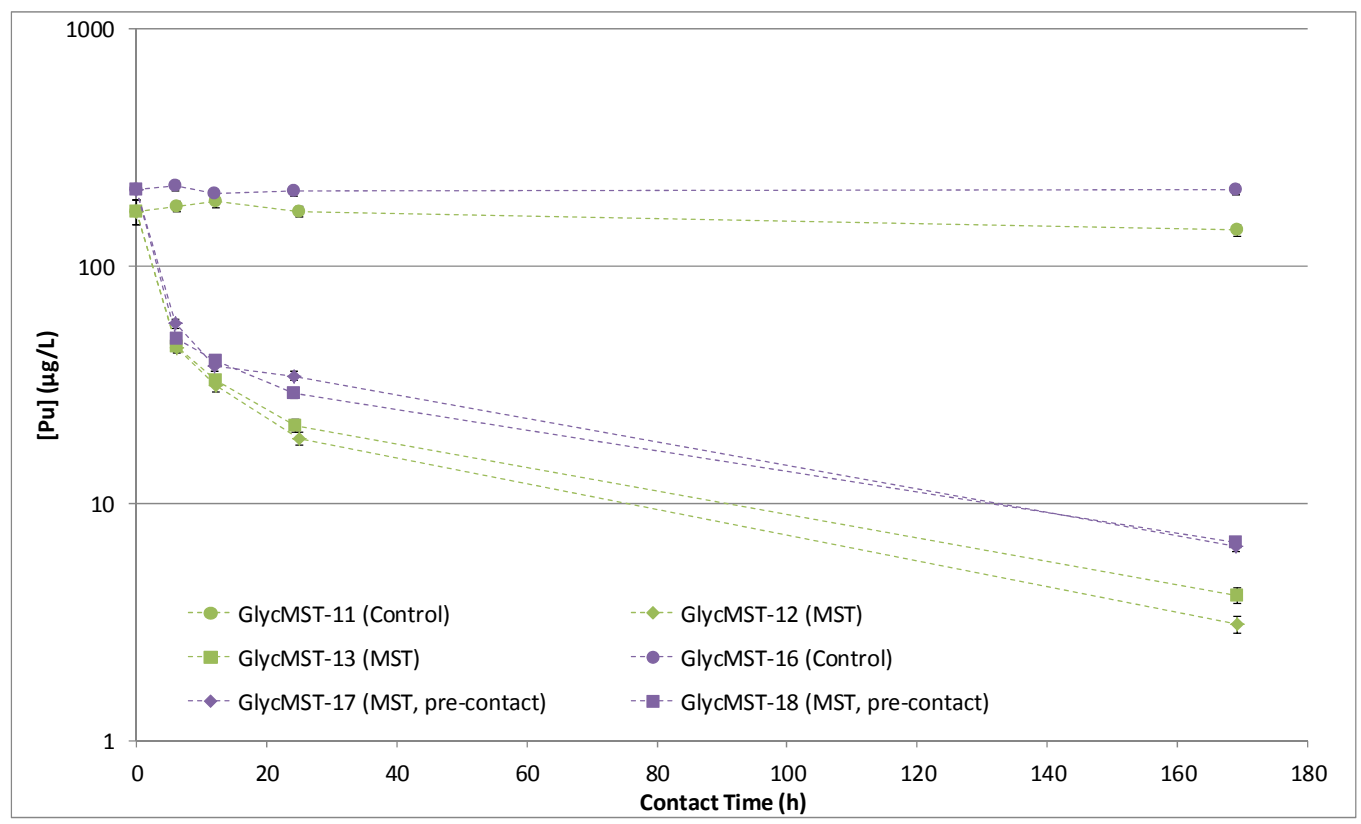

Figure B-6. Pu concentration versus contact time with MST in the presence of $\mathbf{1 0 0 0 0} \mathbf{p p m}$ glycolate with (purple) and without (green) pre-contacting the glycolate with the MST. 
SRNL-STI-2012-00218

Revision 0

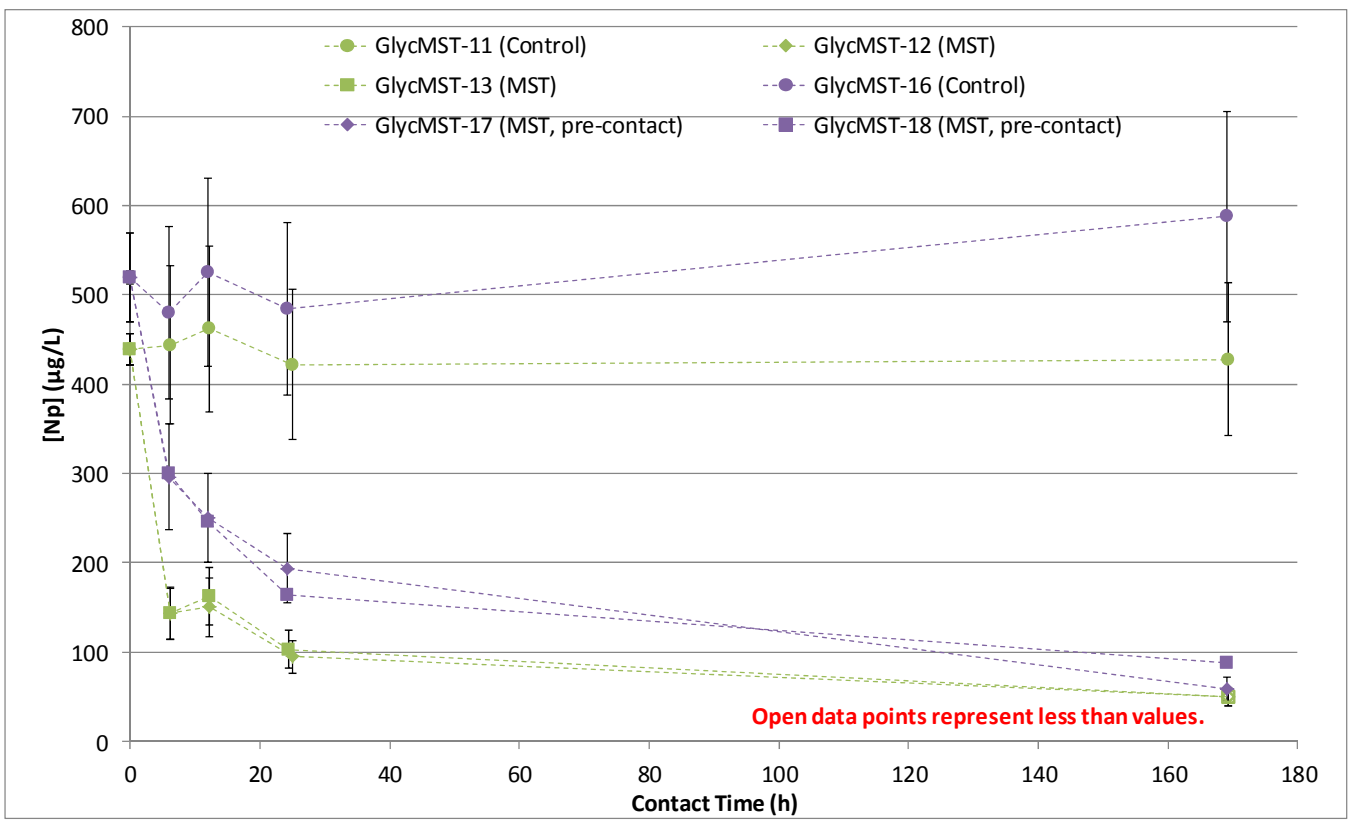

Figure B-7. Np concentration versus contact time with MST in the presence of $10000 \mathrm{ppm}$ glycolate with (purple) and without (green) pre-contacting the glycolate with the MST.

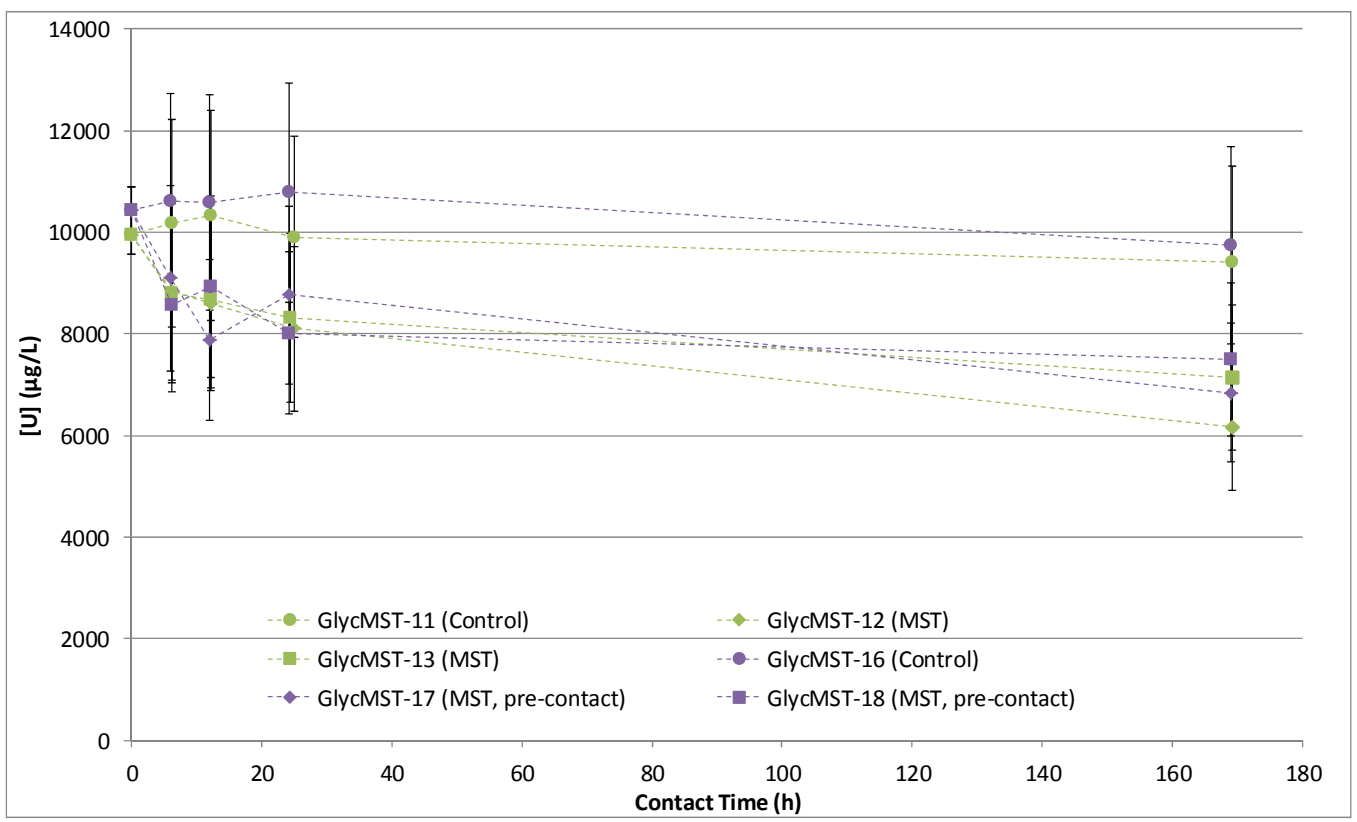

Figure B-8. U concentration versus contact time with MST in the presence of $10000 \mathbf{p p m}$ glycolate with (purple) and without (green) pre-contacting the glycolate with the MST. 
Table B-1. ${ }^{85} \mathrm{Sr}$ DFs for MST in the presence of 0,5000 , and $10000 \mathrm{ppm}$ glycolate. The values represent the average of two replicate trials, with the standard deviations given in parenthesis.

\begin{tabular}{|c|c|c|c|c||}
\hline \hline \multirow{2}{*}{ Time (h) } & \multirow{2}{*}{ 0 ppm glycolate } & \multirow{2}{*}{$\mathbf{5 0 0 0} \mathbf{~ p p m}$ glycolate } & \multicolumn{2}{|c|}{$\mathbf{1 0 0 0 0}$ ppm glycolate } \\
\cline { 4 - 5 } & & & In simulant & Pre-contact w/MST \\
\hline $\mathbf{6}$ & $64.6(3.10)$ & $49.7(2.77)$ & $40.2(0.663)$ & $44.6(1.80)$ \\
\hline $\mathbf{1 2}$ & $76.9(8.39)$ & $61.3(1.99)$ & $44.3(0.686)$ & $54.4(2.29)$ \\
\hline $\mathbf{2 4}$ & $81.2(4.52)$ & $73.6(2.24)$ & $51.5(0.723)$ & $62.3(11.9)$ \\
\hline $\mathbf{1 6 8}$ & $106(11.1)$ & $70.2(26.6)$ & $68.3(14.8)$ & $75.4(11.3)$ \\
\hline
\end{tabular}

Table B-2. Pu DFs for MST in the presence of 0, 5000, and $10000 \mathrm{ppm}$ glycolate. The values represent the average of two replicate trials, with the standard deviations given in parenthesis.

\begin{tabular}{|c|c|c|c|c||}
\hline \multirow{2}{*}{ Time (h) } & \multirow{2}{*}{ 0 ppm glycolate } & \multirow{2}{*}{$\mathbf{5 0 0 0}$ ppm glycolate } & \multicolumn{2}{|c|}{$\mathbf{1 0 0 0 0}$ ppm glycolate } \\
\cline { 4 - 5 } & & & In simulant & Pre-contact w/MST \\
\hline $\mathbf{6}$ & $5.31(0.066)$ & $5.08(0.141)$ & $3.92(0.054)$ & $4.14(0.428)$ \\
\hline $\mathbf{1 2}$ & $7.07(0.286)$ & $7.07(0.200)$ & $5.84(0.197)$ & $5.18(0.168)$ \\
\hline $\mathbf{2 4}$ & $8.60(0.617)$ & $10.5(0.256)$ & $8.51(0.765)$ & $6.61(0.809)$ \\
\hline $\mathbf{1 6 8}$ & $26.8(0.549)$ & $41.6(12.1)$ & $40.3(7.91)$ & $31.4(0.885)$ \\
\hline
\end{tabular}

Table B-3. Np DFs for MST in the presence of 0, 5000, and $10000 \mathrm{ppm}$ glycolate. The values represent the average of two replicate trials, with the standard deviations given in parenthesis.

\begin{tabular}{|c|c|c|c|c||}
\hline \multirow{2}{*}{ Time (h) } & \multirow{2}{*}{ 0 ppm glycolate } & \multirow{2}{*}{$\mathbf{5 0 0 0}$ ppm glycolate } & \multicolumn{2}{|c|}{ 10000 ppm glycolate } \\
\cline { 4 - 5 } & & & In simulant & Pre-contact w/MST \\
\hline $\mathbf{6}$ & $1.34(0.010)$ & $3.67(0.147)$ & $3.10(0.006)$ & $1.61(0.015)$ \\
\hline $\mathbf{1 2}$ & $1.48(0.143)$ & $4.48(0.815)$ & $2.95(0.155)$ & $2.12(0.024)$ \\
\hline $\mathbf{2 4}$ & $1.57(0.076)$ & $6.22(0.061)$ & $4.28(0.263)$ & $2.72(0.313)$ \\
\hline $\mathbf{1 6 8}$ & $4.22(0.397)$ & $>8.10(1.04)$ & $>8.56(0.000)$ & $8.39(2.37)$ \\
\hline
\end{tabular}

Table B-4. U DFs for MST in the presence of 0, 5000, and $10000 \mathrm{ppm}$ glycolate. The values represent the average of two replicate trials, with the standard deviations given in parenthesis.

\begin{tabular}{||c|c|c|c|c||}
\hline \multirow{2}{*}{ Time (h) } & \multirow{2}{*}{ 0 ppm glycolate } & \multirow{2}{*}{$\mathbf{5 0 0 0}$ ppm glycolate } & \multicolumn{2}{|c|}{$\mathbf{1 0 0 0 0}$ ppm glycolate } \\
\cline { 4 - 5 } & & & In simulant & Pre-contact w/MST \\
\hline $\mathbf{6}$ & $1.17(0.046)$ & $1.16(0.049)$ & $1.15(0.006)$ & $1.20(0.052)$ \\
\hline $\mathbf{1 2}$ & $1.19(0.006)$ & $1.24(0.044)$ & $1.20(0.008)$ & $1.27(0.111)$ \\
\hline $\mathbf{2 4}$ & $1.23(0.006)$ & $1.24(0.026)$ & $1.21(0.023)$ & $1.29(0.080)$ \\
\hline $\mathbf{1 6 8}$ & $1.42(0.019)$ & $1.46(0.047)$ & $1.42(0.148)$ & $1.36(0.089)$ \\
\hline
\end{tabular}


SRNL-STI-2012-00218

Revision 0

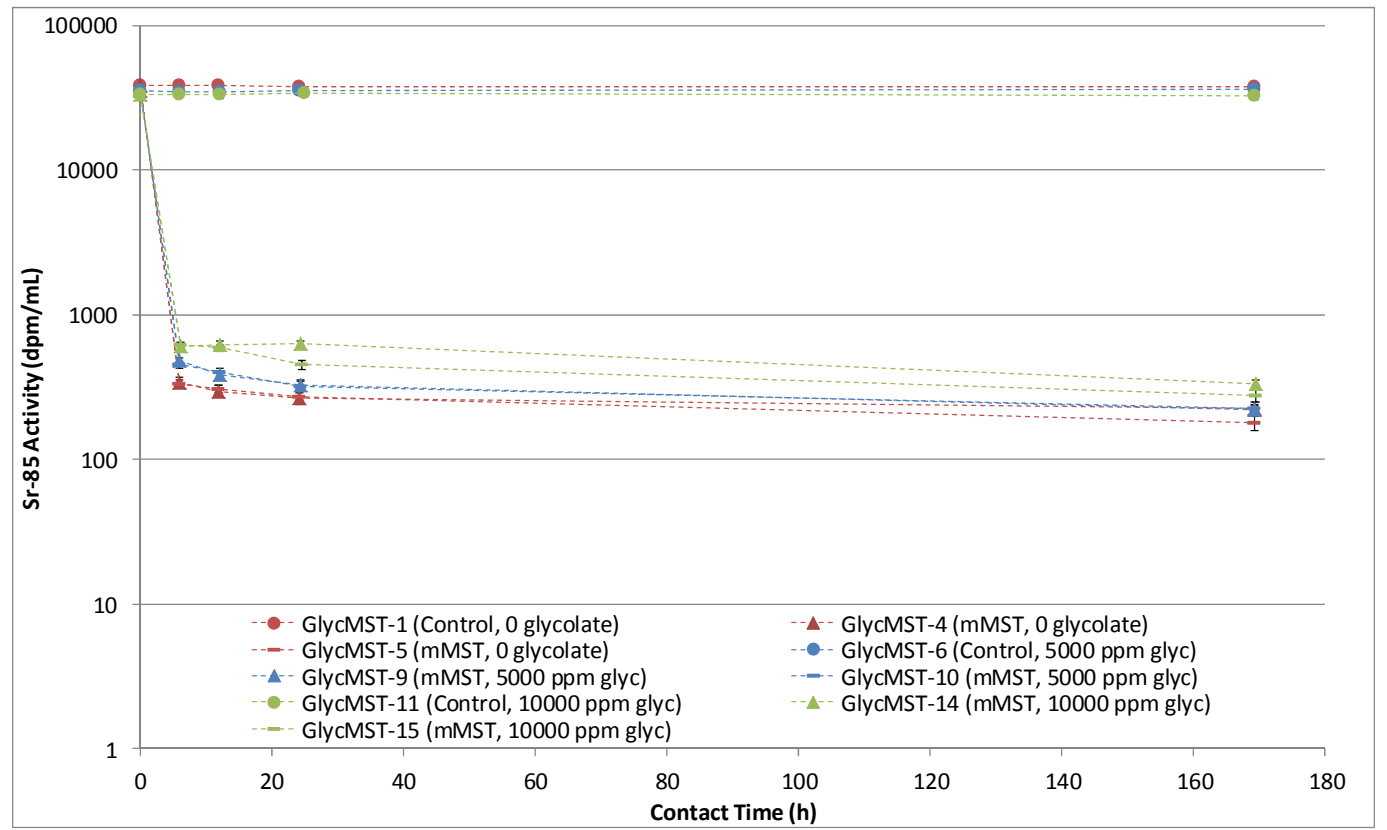

Figure B-9. ${ }^{85} \mathrm{Sr}$ activity versus contact time with $\mathrm{mMST}$ in the presence of $0 \mathrm{ppm}$ (red), 5000 ppm (blue), or 10000 ppm (green) glycolate.

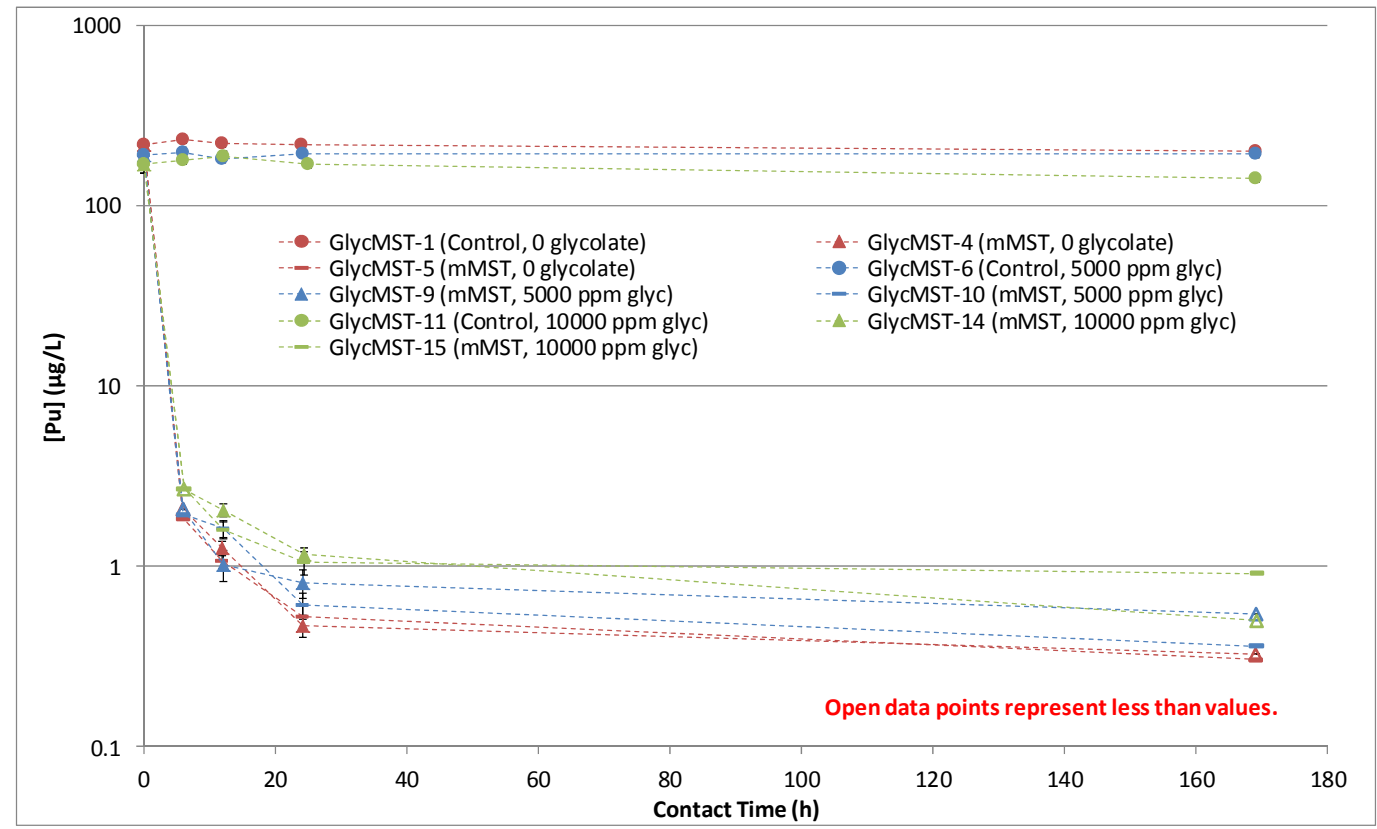

Figure B-10. Pu concentration versus contact time with $\mathrm{mMST}$ in the presence of $0 \mathrm{ppm}$ (red), 5000 ppm (blue), or 10000 ppm (green) glycolate. 
SRNL-STI-2012-00218

Revision 0

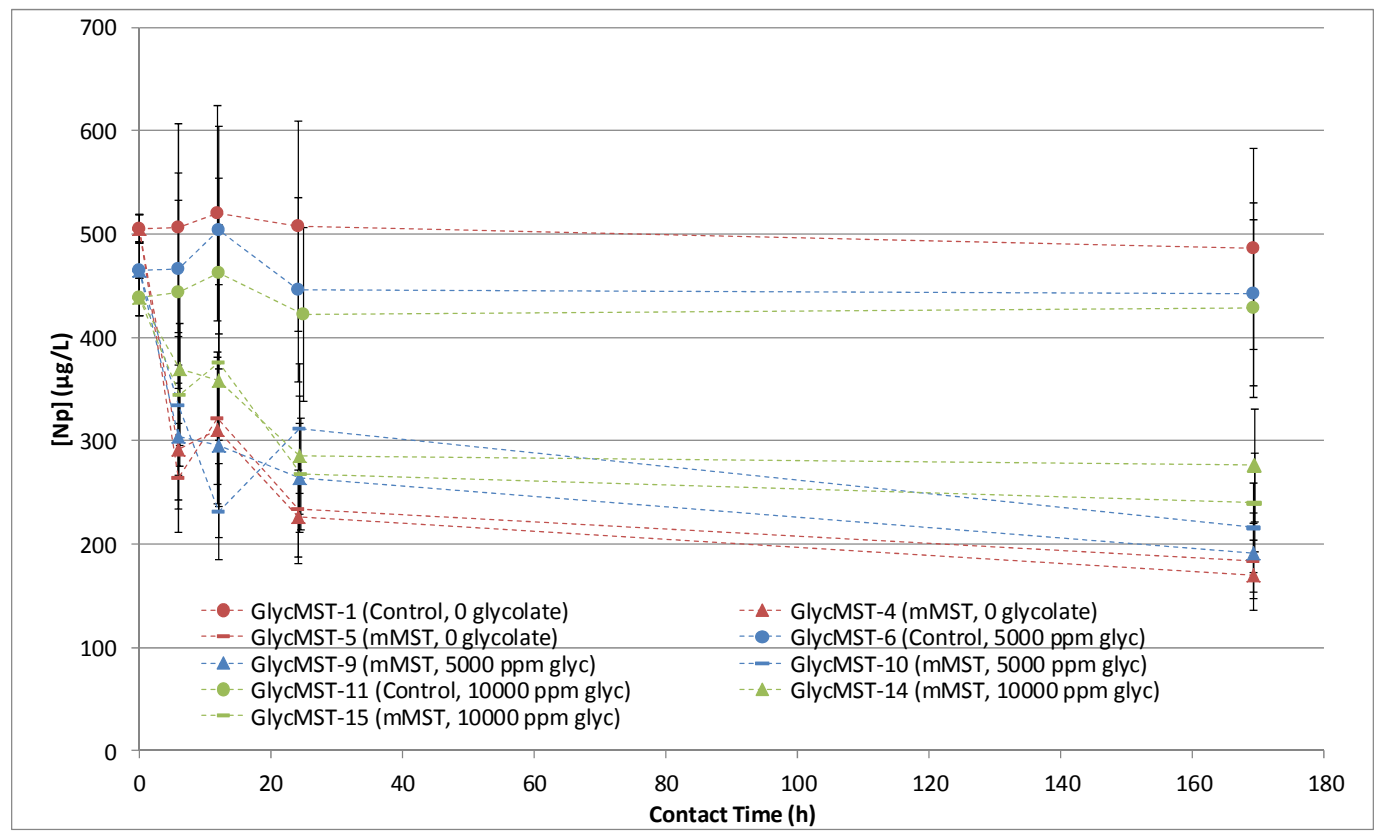

Figure B-11. Np concentration versus contact time with mMST in the presence of $0 \mathbf{p p m}$ (red), 5000 ppm (blue), or 10000 ppm (green) glycolate.

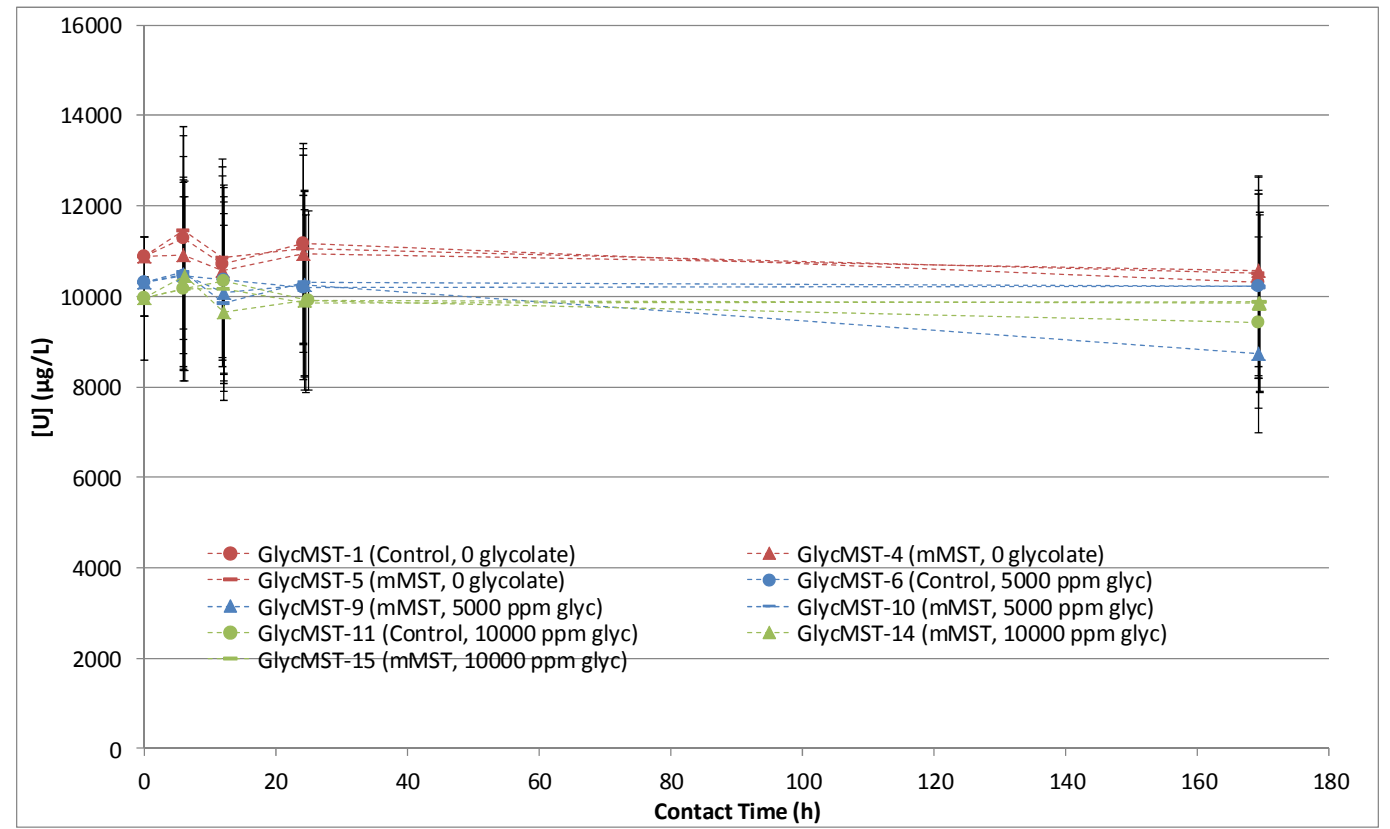

Figure B-12. U concentration versus contact time with mMST in the presence of 0 ppm (red), 5000 ppm (blue), or 10000 ppm (green) glycolate. 
SRNL-STI-2012-00218

Revision 0

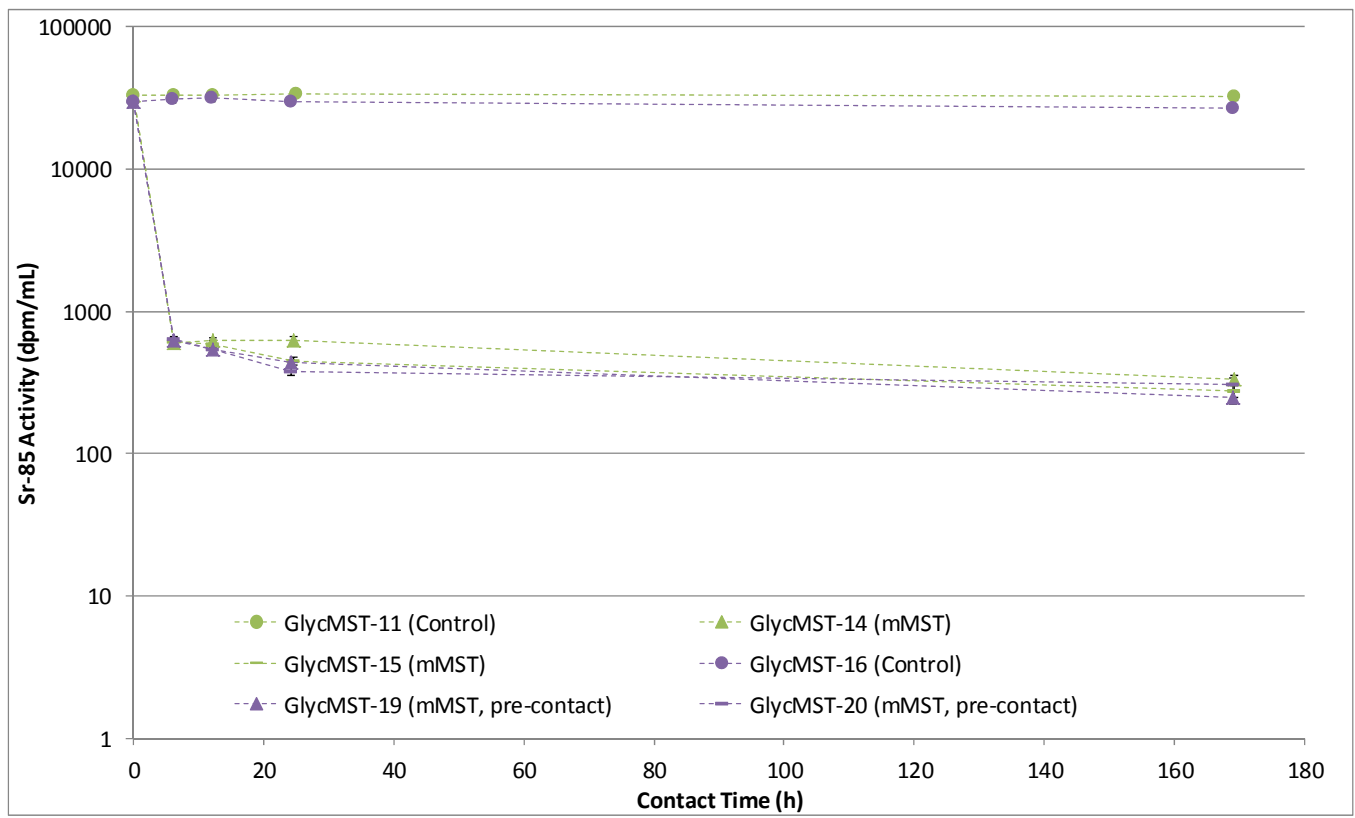

Figure B-13. ${ }^{85} \mathrm{Sr}$ activity versus contact time with $\mathrm{mMST}$ in the presence of $10000 \mathrm{ppm}$ glycolate with (purple) and without (green) pre-contacting the glycolate with the mMST.

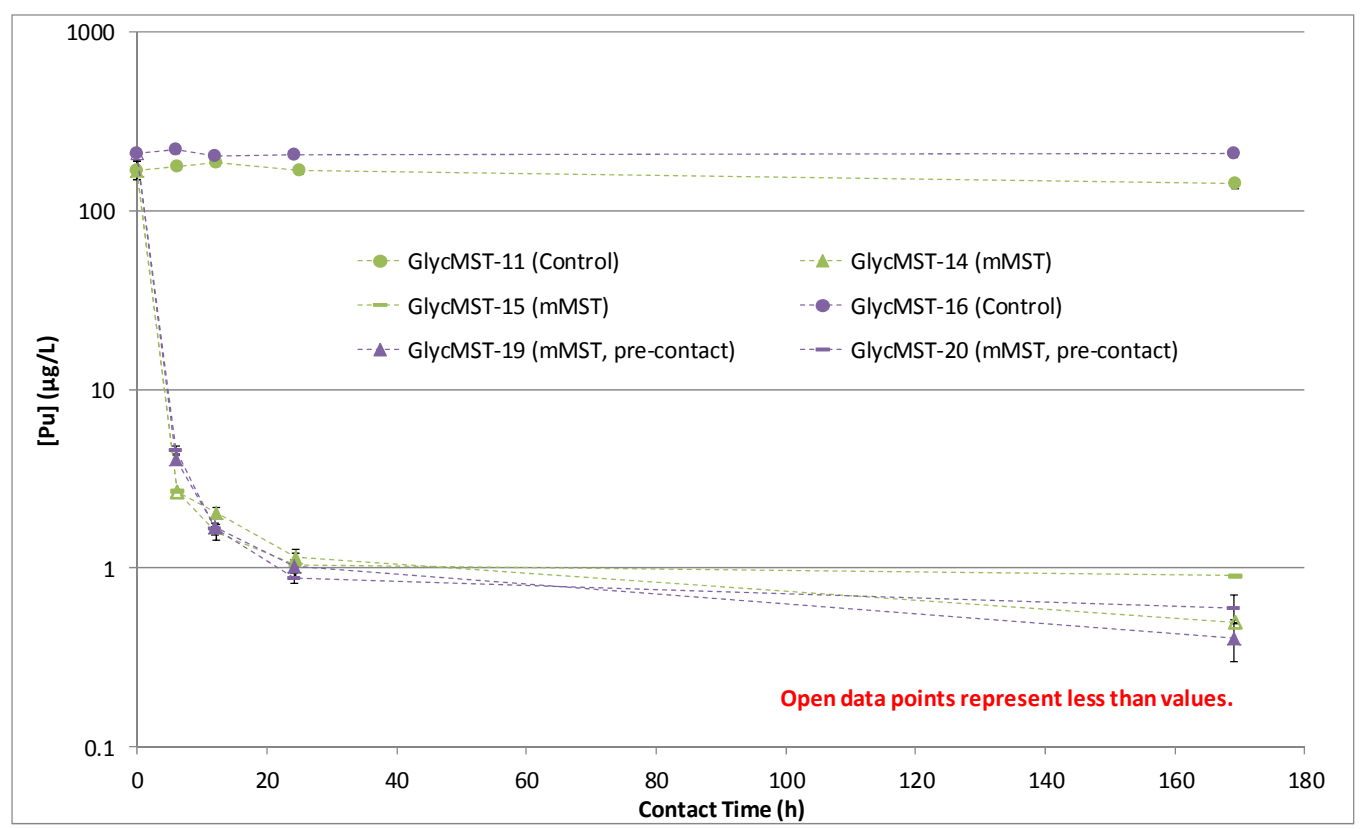

Figure B-14. Pu concentration versus contact time with mMST in the presence of 10000 ppm glycolate with (purple) and without (green) pre-contacting the glycolate with the mMST. 
SRNL-STI-2012-00218

Revision 0

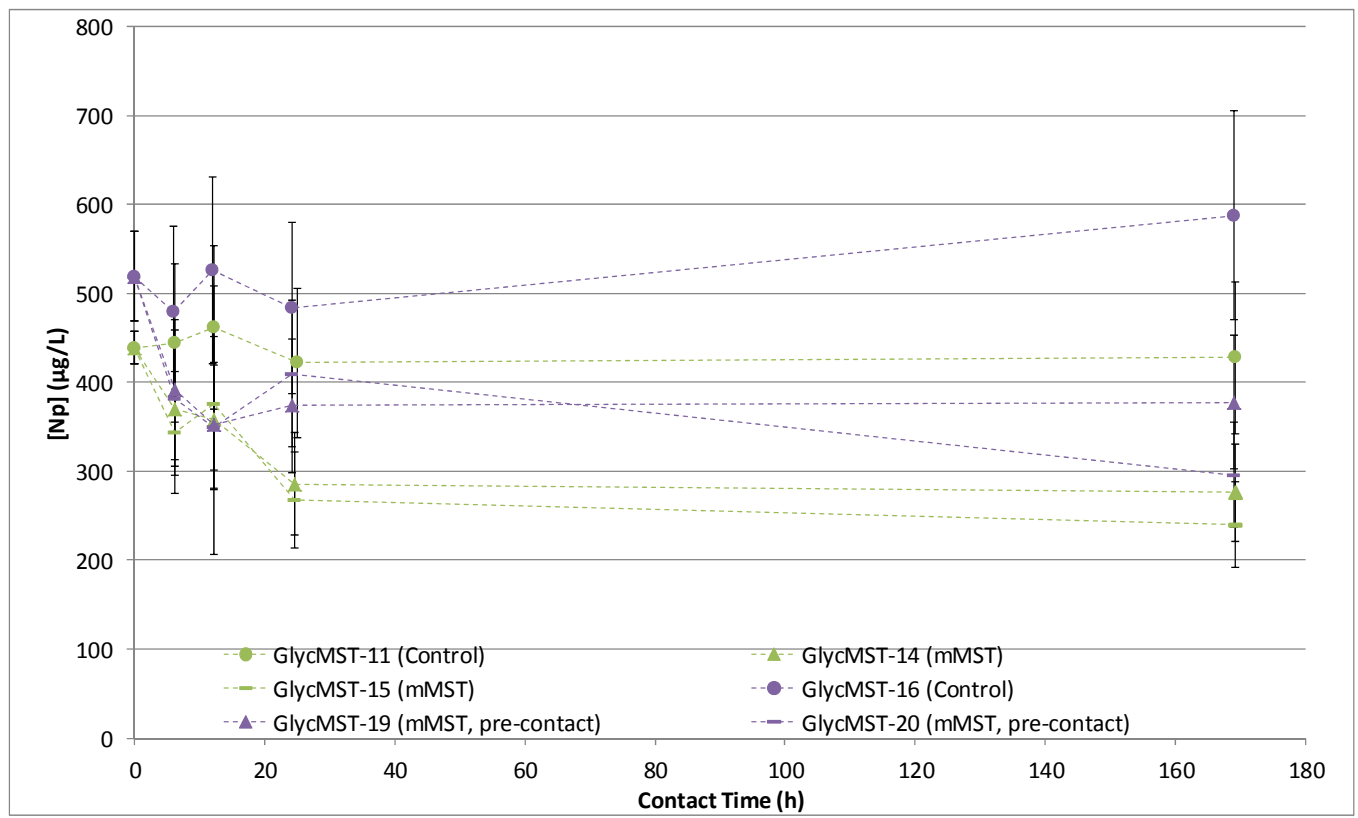

Figure B-15. Np concentration versus contact time with mMST in the presence of $\mathbf{1 0 0 0 0}$ ppm glycolate with (purple) and without (green) pre-contacting the glycolate with the mMST.

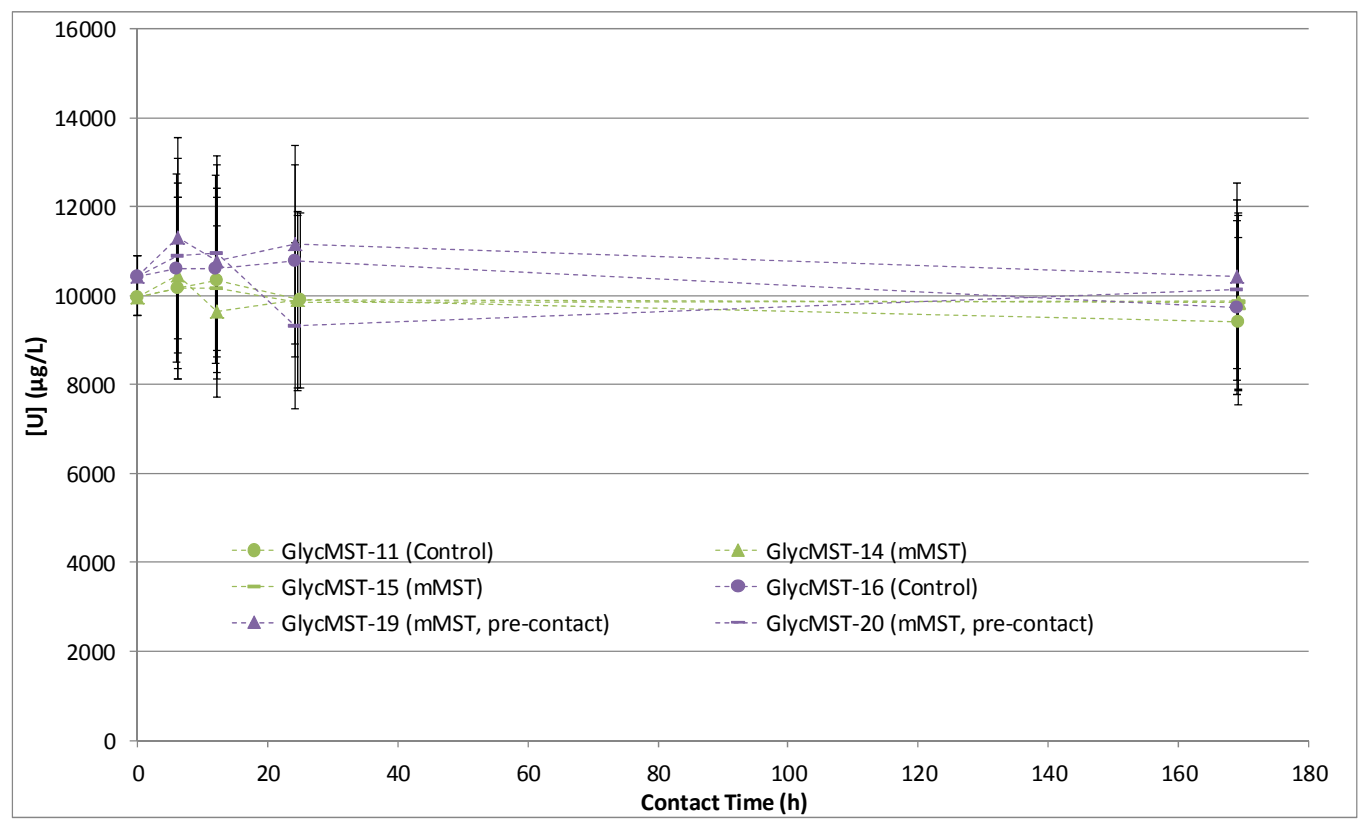

Figure B-16. U concentration versus contact time with $\mathrm{mMST}$ in the presence of $10000 \mathrm{ppm}$ glycolate with (purple) and without (green) pre-contacting the glycolate with the mMST. 
Table B-5. ${ }^{85} \mathrm{Sr}$ DFs for mMST in the presence of 0,5000 , and $10000 \mathrm{ppm}$ glycolate. The values represent the average of two replicate trials, with the standard deviations given in parenthesis.

\begin{tabular}{|c|c|c|c|c||}
\hline \hline \multirow{2}{*}{ Time (h) } & \multirow{2}{*}{ 0 ppm glycolate } & \multirow{2}{*}{$\mathbf{5 0 0 0} \mathbf{p p m}$ glycolate } & \multicolumn{2}{|c|}{$\mathbf{1 0 0 0 0}$ ppm glycolate } \\
\cline { 4 - 5 } & & & In simulant & Pre-contact w/MST \\
\hline $\mathbf{6}$ & $115(2.80)$ & $74.7(2.87)$ & $55.0(1.02)$ & $49.2(0.885)$ \\
\hline $\mathbf{1 2}$ & $126(3.13)$ & $87.8(3.30)$ & $54.8(2.02)$ & $58.5(0.077)$ \\
\hline $\mathbf{2 4}$ & $142(1.93)$ & $109(1.16)$ & $64.6(15.3)$ & $74.4(7.32)$ \\
\hline $\mathbf{1 6 8}$ & $190(28.3)$ & $162(2.51)$ & $107(15.2)$ & $98.4(14.6)$ \\
\hline
\end{tabular}

Table B-6. Pu DFs for mMST in the presence of 0, 5000, and $10000 \mathrm{ppm}$ glycolate. The values represent the average of two replicate trials, with the standard deviations given in parenthesis.

\begin{tabular}{||c|c|c|c|c||}
\hline \multirow{2}{*}{ Time (h) } & \multirow{2}{*}{ 0 ppm glycolate } & \multirow{2}{*}{$\mathbf{5 0 0 0}$ ppm glycolate } & \multicolumn{2}{|c|}{$\mathbf{1 0 0 0 0}$ ppm glycolate } \\
\cline { 4 - 5 } & & & In simulant & Pre-contact w/MST \\
\hline $\mathbf{6}$ & $>119(9.89)$ & $>99.2(4.94)$ & $>66.7(0.452)$ & $50.8(3.70)$ \\
\hline $\mathbf{1 2}$ & $191(21.9)$ & $145(45.7)$ & $105(18.2)$ & $>121(1.28)$ \\
\hline $\mathbf{2 4}$ & $436(34.0)$ & $278(57.1)$ & $155(10.9)$ & $220(23.2)$ \\
\hline $\mathbf{1 6 8}$ & $>642(31.7)$ & $>449(128)$ & $>220(91.3)$ & $434(115)$ \\
\hline
\end{tabular}

Table B-7. Np DFs for mMST in the presence of 0, 5000, and $10000 \mathrm{ppm}$ glycolate. The values represent the average of two replicate trials, with the standard deviations given in parenthesis.

\begin{tabular}{|c|c|c|c|c|}
\hline \multirow{2}{*}{ Time (h) } & \multirow{2}{*}{ 0 ppm glycolate } & \multirow{2}{*}{$\mathbf{5 0 0 0}$ ppm glycolate } & \multicolumn{2}{|c|}{$\mathbf{1 0 0 0 0}$ ppm glycolate } \\
\cline { 4 - 5 } & & & In simulant & Pre-contact w/MST \\
\hline $\mathbf{6}$ & $1.82(0.130)$ & $1.46(0.097)$ & $1.25(0.064)$ & $1.24(0.023)$ \\
\hline $\mathbf{1 2}$ & $1.65(0.044)$ & $1.94(0.332)$ & $1.26(0.044)$ & $1.50(0.006)$ \\
\hline $\mathbf{2 4}$ & $2.21(0.054)$ & $1.56(0.184)$ & $1.53(0.070)$ & $1.24(0.080)$ \\
\hline $\mathbf{1 6 8}$ & $2.75(0.147)$ & $2.18(0.183)$ & $1.67(0.164)$ & $1.77(0.305)$ \\
\hline
\end{tabular}

Table B-8. U DFs for mMST in the presence of 0,5000 , and $10000 \mathrm{ppm}$ glycolate. The values represent the average of two replicate trials, with the standard deviations given in parenthesis.

\begin{tabular}{|c|c|c|c|c||}
\hline \multirow{2}{*}{ Time (h) } & \multirow{2}{*}{ 0 ppm glycolate } & \multirow{2}{*}{$\mathbf{5 0 0 0}$ ppm glycolate } & \multicolumn{2}{|c|}{$\mathbf{1 0 0 0 0}$ ppm glycolate } \\
\cline { 4 - 5 } & & & In simulant & Pre-contact w/MST \\
\hline $\mathbf{6}$ & $1.01(0.034)$ & $0.993(0.004)$ & $0.987(0.019)$ & $0.957(0.024)$ \\
\hline $\mathbf{1 2}$ & $1.00(0.020)$ & $1.04(0.016)$ & $1.04(0.040)$ & $0.974(0.010)$ \\
\hline $\mathbf{2 4}$ & $1.01(0.008)$ & $0.992(0.003)$ & $1.00(0.006)$ & $1.06(0.133)$ \\
\hline $\mathbf{1 6 8}$ & $0.977(0.003)$ & $1.09(0.122)$ & $0.955(0.003)$ & $0.947(0.020)$ \\
\hline
\end{tabular}




\section{Distribution:}

S. D. Fink, 773-A

K. M. Fox, 999-W

B. J. Giddings, 786-5A

C. C. Herman, 999-W

S. L. Marra, 773-A

F. M. Pennebaker, 773-42A

W. R. Wilmarth, 773-A

Records Administration (EDWS)

J. M. Bricker, 704-27S

T. L. Fellinger, 704-26S

J. M. Gillam, 766-H

B. A. Hamm, 766-H

E. W. Holtzscheiter, 704-15S

J. F. Iaukea, 704-30S

M. T. Keefer, 241-156H

D. P. Lambert, 999-W

D. W. McIlmoyle, 766-H

J. E. Occhipinti, 704-S

D. K. Peeler, 999-W

W. O. Pepper, 704-S

J. W. Ray, 704-S

M. A. Rios-Armstrong, 241-156H

H. B. Shah, 766-H

D. C. Sherburne, 704-S

A. V. Staub, 704-27S

M. E. Stone, 999-W

P. R. Jackson, DOE-SR, 703-46A

K. H. Subramanian, 766-H
K. M. L. Taylor-Pashow, 773-A

T. C. Shehee, 773-A

D. T. Hobbs, 773-A

T. B. Peters, 773-42A

F. F. Fondeur, 773-A 